\title{
Landscape of Myeloid-derived Suppressor Cell in Tumor Immunotherapy
}

\author{
Zhaonian Hao ${ }^{1}$, Ruyuan $\mathrm{Li}^{2,3}$, Yuanyuan Wang ${ }^{2}$, Shuangying $\mathrm{Li}^{2}$, Zhenya Hong ${ }^{4^{*}}$ and Zhiqiang Han²*
}

\begin{abstract}
Myeloid-derived suppressor cells (MDSC) are a group of immature cells that produced by emergency myelopoiesis. Emerging evidences have identified the vital role of MDSC in cancer microenvironment, in which MDSC exerts both immunological and non-immunological activities to assist the progression of cancer. Advances in pre-clinical research have provided us the understanding of MDSC in cancer context from the perspective of molecular mechanism. In clinical scenario, MDSC and its subsets have been discovered to exist in peripheral blood and tumor site of patients from various types of cancers. In this review, we highlight the clinical value of MDSC in predicting prognosis of cancer patients and the responses of immunotherapies, therefore to propose the MDSC-inhibiting strategy in the scenario of cancer immunotherapies. Phenotypes and biological functions of MDSC in cancer microenvironment are comprehensively summarized to provide potential targets of MDSC-inhibiting strategy from the aspect of molecular mechanisms.
\end{abstract}

Keywords: Myeloid-derived suppressor cells, Tumor, Immunotherapy

\section{Background}

Since the approval of ipilimumab (Yervoy) and pembrolizumab/nivolumab (Keytruda and Opdivo) in 2011 and 2014, respectively, by FDA, a new era began in the field of tumor immunotherapy. Along with CAR-T therapy, the immunotherapy therefore became a new frontier and new hope in prolonging the clinical benefit of cancer patients. Performances have been achieved of immunotherapy in treating some specific types of tumors $[1,2]$, however limited anti-tumor activity has also been reported in several types of tumors. As the aftermath of intensive immunological researches that have been launched in recent years, the scientific community has reached a consensus that several specific types of

\footnotetext{
*Correspondence: hongzhenya@126.com; hanzq2003@126.com

${ }^{4}$ Department of Hematology, Tongji Hospital, Tongji Medical College, Huazhong University of Science and Technology, Wuhan 430030, Hubei, China

${ }^{2}$ Department of Obstetrics and Gynecology, Tongji Hospital, Tongji Medical College, Huazhong University of Science and Technology, Wuhan 430030, Hubei, China

Full list of author information is available at the end of the article
}

immune cells have been identified to play great roles in tumor microenvironment. Among them, regulatory $\mathrm{T}$ cells (Tregs), tumor-associated macrophages (TAMs), and type 2 helper $\mathrm{CD}_{4}^{+}$(Th2) T cells have been revealed to mediate significant immunosuppressive activity in the tumor context, along with myeloid-derived suppressor cells (MDSCs), a newly discovered population of immune-related cell with immunosuppressive potential [3]. Accumulative evidence has proposed that these immunosuppressive populations contribute to impairing of CD8+ T cell and natural killer (NK) cell, which may further lead to poor response of immunotherapy [4].

MDSC was discovered in the pathological condition of emergency myelopoiesis that is induced by disrupted leukopoiesis. This emergency myelopoiesis is a type of solution to the critical situations (such as infection, cancer, or wound), however, prolonged or chronical conditions eventually lead to the accumulation of immature myeloid cells out of standard differentiation route. The term "MDSC" was suggested by researchers in 2007 to describe a group of immature cells according to their 
origin and biological functions, which was found to have significant expansion in cancer-related microenvironment [5]. At present, most studies on MDSC are still in an earlier stage, and limited consensus was reached on issues or problems about MDSC, such as molecular markers, heterogeneity in different cancers, and detailed mechanism of immunosuppression.

In this review, we systematically summarize the current progress of molecular markers and biological functions of MDSC. Especially, we emphasized the critical prognosis monitoring value of MDSC, and therefore proposed the vital status of MDSC in cancer immunotherapies.

\section{Phenotypes of MDSC}

Since the discovery of MDSC, multiple molecular markers have been proposed to define the MDSC population, and HLA-DR ${ }^{-} \mathrm{Lin}^{\text {low/- }} \mathrm{CD} 3^{+} \mathrm{CD} 11 \mathrm{~b}^{+}$ label is commonly used for MDSC recognition, which has also been widely discussed in previous reports [6, 7]. Specific phenotypes or subsets of MDSC have also been previously discussed in reviews [8-10]. A consensus has been reached to a certain extent that MDSC can be typically distinguished as polymorphonuclear and monocytic MDSC, abbreviated as PMN-MDSC and M-MDSC, respectively. Among human peripheral blood mononuclear cells (PBMCs), PMN-MDSC is generally described as

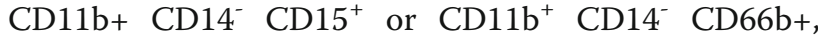
while M-MDSC is generally described as CD11b+ CD $14^{+}$HLA-DR $^{-/ \text {low }} \mathrm{CD} 15^{+}$. Lin $^{-}$(including CD3, CD14, CD15, CD19, CD56) HLA-DR ${ }^{-} \mathrm{CD}^{+}{ }^{+}$cells is a mixed group of MDSC that tends to be more immature. And immature-MDSC (i-MDSC) or earlystage (e-MDSC) has been proposed to define these subsets [8].

As MDSC is identified to be a vital participant in tumor microenvironment and is revealed to act differently in specific tissues or tumors $[6,11]$, we systematically summarized the atlas of MDSC phenotypes in the peripheral blood or tumor site that have been reported in pan-cancer researches $[6,7,11-15]$ (Figs 1 and 2). Interestingly, a novel subset of $\mathrm{Lin}^{-}$HLA-DR

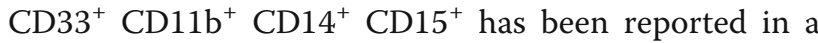
study of non-small cell lung cancer (NSCLC), in which the $\mathrm{CD} 14^{+} \mathrm{CD} 15^{+}$population was revealed to have a satisfactory prognostic value in untreated patients [16].

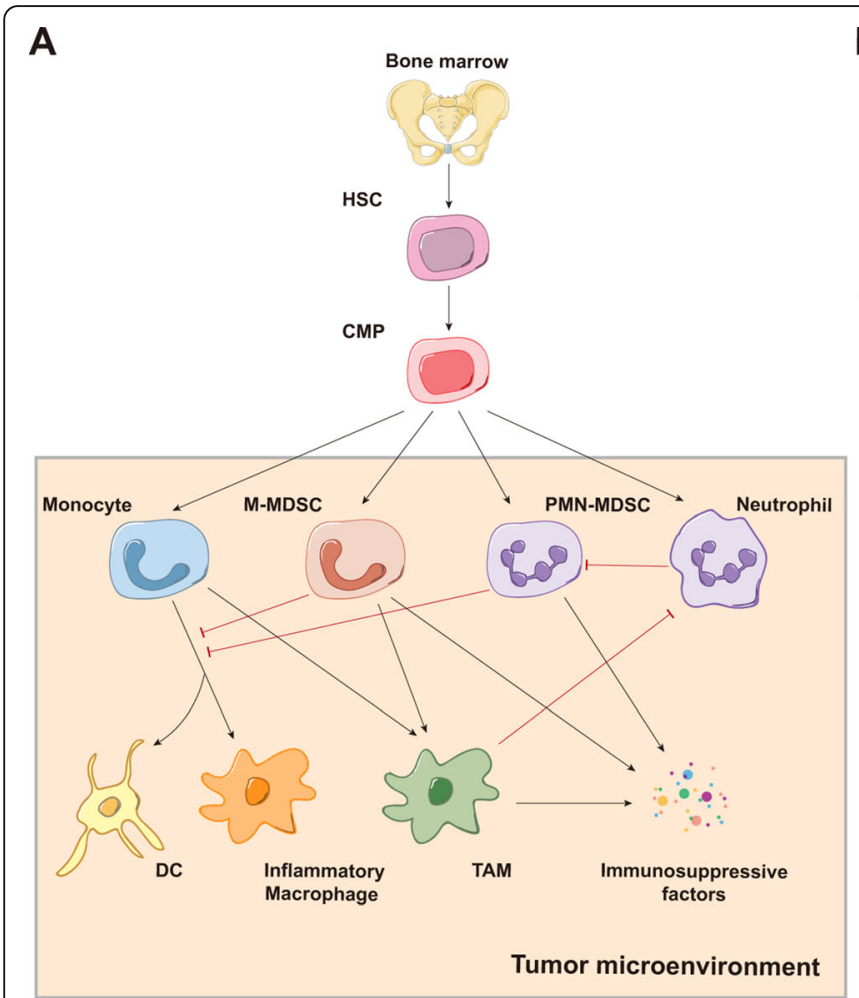

B
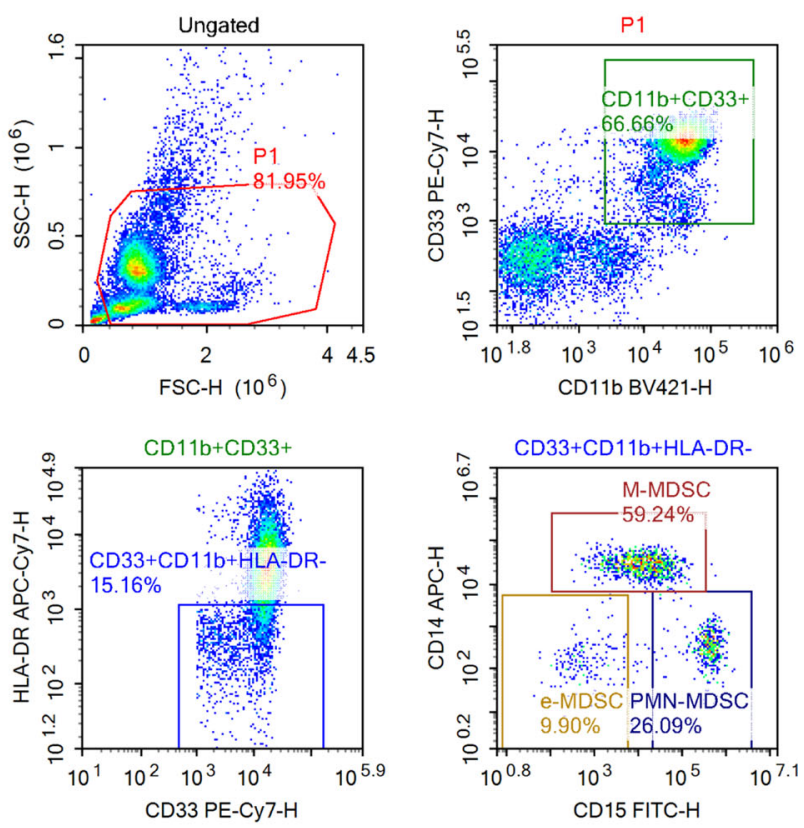

Fig. 1 Representative picture of MDSC and flow cytometry data. A: Representative figure of origin, differentiation, and characteristics of MDSC in tumor microenvironment. B: Representative flow cytometry of MDSC isolation and gating strategy. Abbreviations: MDSC, Myeloid-derived suppressor cell; HSC, Hematopoietic stem cell; CMP, Common myeloid precursor cell; M-MDSC, Monocytic MDSC; PMN-MDSC, Polymorphonuclear MDSC; DC, Dendritic cell; TAM, Tumor associated macrophage. Abbreviations: MDSC, Myeloid-derived suppressor cell; M-MDSC, Monocytic MDSC; PMN-MDSC, Polymorphonuclear MDSC; eMDSC, early-stage MDSC 


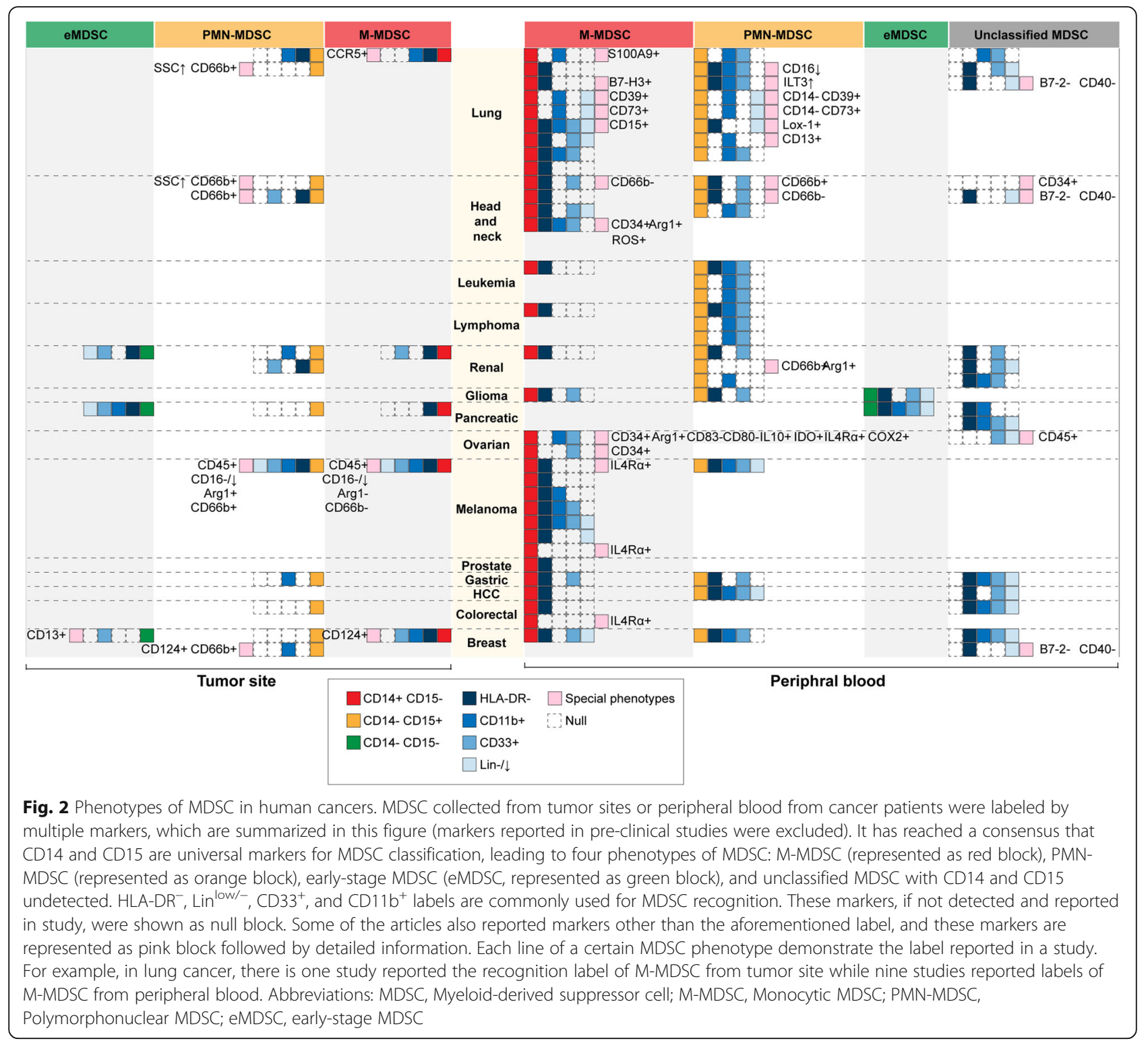

Some novel surface markers have been proposed for MDSC subsets and functioning recognition, such as an IL-4R $\alpha$ expressing population of M-MDSC can exert critical inhibition on CD8 $+\mathrm{T}$ cells in colorectal cancer and melanoma [17]. Expression of a STAT3 dephosphorylase, $\mathrm{CD} 45$, has been identified in a group of MDSC, frequency of which in tumor site and peripheral blood is closely correlated with tumor stage and clinical outcomes [18]. Ectonucleotidases CD39 and CD73, which catalyze the conversion of ATP/ADP to adenosine, have been detected on the surface of a specific group of MDSC in lung cancer, which is significantly associated with the chemotherapy response of patients [12].

\section{MDSC in tumor microenvironment}

\section{MDSC recruitment and maintenance}

Recruitment and maintenance, two key steps in the involvement of MDSC in cancer progression, initiate the enduring MDSC-induced impact in the cancer microenvironment. Cytokine effects and specific ligandreceptor binding are marked significant in MDSC attraction, while anti-apoptosis effects are considered primary process in MDSC survival in the cancer context (Fig 3).

The chemokine family plays an important role in MDSC attraction, in which the binding of chemokines to their receptors triggers great impact on migration. Pairwise effects of chemokines and receptors are widely observed in MDSC motivation, including CCL2/CCR 


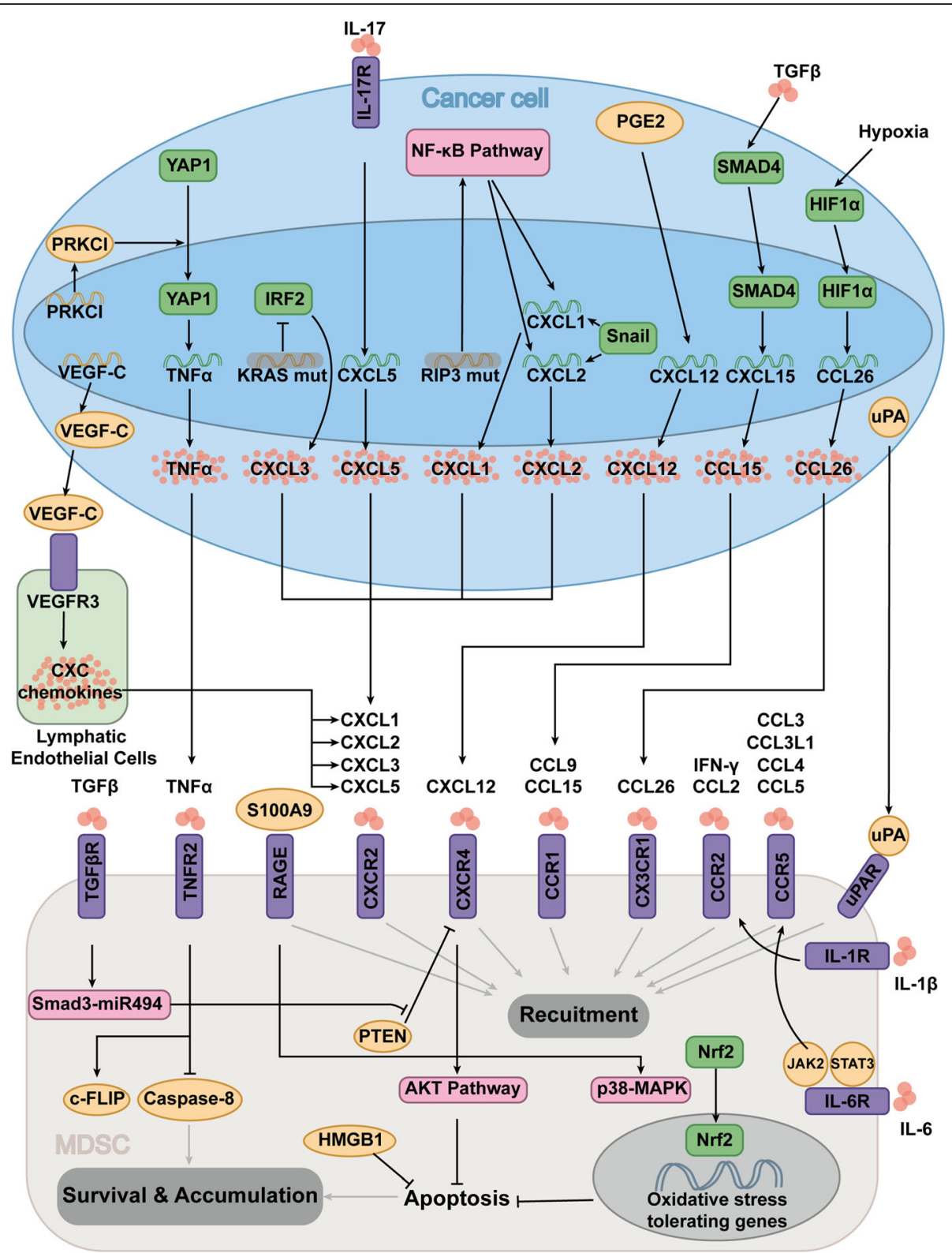

Fig. 3 Mechanisms of MDSC maintenance and accumulation in tumor microenvironment. Abbreviations: MDSC, Myeloid-derived suppressor cell

2[19], CCL15/CCR 1[20], CCL9/CCR 1[21], CXCL1/ CXCL2/CXCL3 with receptor CXCR 2[22-25], CXCL12/CXCR 4[26, 27], and CXCL8 (IL-8) with receptor CXCR1/CXCR 2[28].

Upregulation of chemokines in the cancer environment is the first scenario of MDSC recruitment, which is conducted by multifarious mechanisms, including driver-gene mutations, genome alterations, and hypoxia in the cancer environment. Loss of SMAD4 is common in colorectal cancer. As a downstream transcription factor of the TGF$\beta$ superfamily, SMAD4 can negatively regulate the expression of CCL15 by binding to the promoter of CCL1 5[29], and CCL15 is upregulated in SMAD4-deficient colorectal cancer, and in which mediates the recruitment of MDSC through a CCL15/CCR1-dependent manner [20]. IRF2 inhibition was found in KRAS-mutated colorectal cancer, contributing to the augmented expression of CXCL3, which binds to CXCR2 on MDSCs to induce migration [25]. Snail, a remarkable transcriptional factor that conducts epithelial-mesenchymal transition (EMT), was identified to upregulate expression of CXCL1/2 through the NF- $\mathrm{KB}$ pathway, which leads to more MDSC infiltration via CXCR2 signaling [23]. The RIP3 deletion in hepatocellular carcinoma (HCC) is revealed to increase the production of chemokine the CXCL1 by activating the NF- $\mathrm{KB}$ pathway, which results in chemoattracting CXCR2 ${ }^{+} \mathrm{MDSC}$ 
into cancer site [24]. Hypoxia in the cancer context induces HIF expression in HCC, and thereupon promotes CCL26 transcription in tumor cells, which subsequently recruits MDSC via CX3CR1 signaling [30]. Additionally, VEGF expression was found to positively correlated with chemokine expression [31]. VEGF-C produced by human breast cancer cell line is demonstrated to promote the expression of multiple intracellular chemokines by interacting with VEGFR3 on the surface of lymphatic endothelial cells, which was identified able to increase CXCR2 ${ }^{+}$MDSC infiltration [32]. Other studies have presented that VEGF R2 blockers can increase the expression of Arg-1, partially reversing the inhibitory effect of M-MDSC on T cell proliferation and decreasing the number of Tregs in tumors [33]. PGE2 is reported to play a role in recruiting MDSC in lung cancer, induced by Fas stimulation [34]. PGE2 is also highly expressed in the ascites of patients with ovarian cancer. The overexpression of PGE2 in the microenvironment of ovarian cancer also induces the production of CXCL12 (SDF1), thereby enhances the mi-

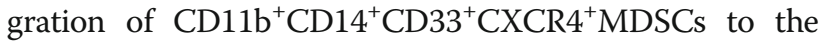
ascites of patients with ovarian cancer [35]. Interleukins like IL-1 $\beta$ and IL-17 are presented on cell surface to recruit MDSC [36, 37]. IL-17 is proclaimed to increase CXCL5 expression of cancer cell, and subsequently enhancing the infiltration of MDSC into the cancer cell cluster in a CXCL5/CXCR2-dependent manner [37]. Moreover, IL-17 is reportedly secreted from CD27- $\gamma \delta \mathrm{T}$ cells as shown in a melanoma mouse model, which mainly causes PMN-MDSC infiltration [38].

In contrast, upregulating of chemokine receptors on the surface of MDSC also supports the chemoattraction effect. Autocrine of PGE2 is reported to promotes the expression of CXCR4 on MDSC [35]. TGF- $\beta$ is also revealed able to upregulate the expression of CXCR4 on the surface of MDSC via restraining of PTEN via the Smad3-miR494 pathway [39].

Core cytokines like TNF $\alpha$ and IFN- $\gamma$ also take part in MDSC infiltration. By inducing nuclear translocation of YAP1, PRKCI increases transcription, expression, and release of TNFa from cancer cells, which subsequently leads to MDSC attraction [40]. Adoptive T-cell immunotherapy (ACT) has been applied in multiple refractory cancers, but its therapeutic effect is often affected by enhanced negative feedback from MDSC recruited in later stages [41, 42], which is related to the secretion of IFN- $\gamma$ in $\mathrm{T}$ cells [42].

Upon specific receptor-ligand interactions, MDSC can also migrate or infiltrate to the cancer environment. Tumor-derived $\mathrm{UPA}$ is revealed to recruit MDSC via the UPA receptor UPAR [43]. S100A9 levels are found to elevated in tumor tissue and peripheral blood of patients with colorectal cancer (CRC), which is capable of promoting MDSC chemotaxis and activation in RAGE- mediated p38/MAPK and TLR4-mediated NF- $\mathrm{kB}$ pathways. S100A9 also participates in the production of immunosuppressive molecules of MDSC, including reactive oxygen species (ROS), Arg1, iNOS, and IL-10 by pairwise binding to its receptor on MDSC [44].

Prevention of apoptosis is found to be closely linked to the survival and maintenance of $\operatorname{MDSC}[27,45,46]$. Apart from augmenting chemotaxis of MDSC by binding to its receptor CXCR4, the chemokine SDF-1 also leads to the activation of the downstream AKT pathway and mediates the reduction of MDSC apoptosis [27]. ROS is an important inhibitor of $\mathrm{T}$ cells produced by MDSC. NF erythroid 2-related factor 2 (Nrf2), a transcription factor that regulates oxidative stress tolerating genes, improves the survival of tumor-infiltrating MDSC by reinforcing their resistance to ROS and reducing apoptosis [45]. High mobility group box protein-1 (HMGB1), a damage-associated molecular pattern molecule (DAMP), has been also shown to protect MDSC by preventing apoptosis [46].

\section{Immunological functions of MDSC}

The major role of MDSC in cancer context is to induce immunoinhibitory effect that supports the immune escape of cancer cells, which is generally conducted via promoting immunosuppression or inhibiting pro-inflammatory cells. To promote those immunosuppression-related cells, MDSC is considered to promote Treg cell proliferation and development in an arginase- and IDO-dependent manner, or through the upregulation of certain ligands for co-stimulation, including PD-L1 and CD8 6[18, 47]. TGF$\beta$, IL-10, and IFN- $\gamma$ were also revealed to facilitate the induction and development in vivo [48, 49]. Further, it has been demonstrated that the crosstalk between MDSC and Treg cell may lead to development of both immunosuppressive cells in a TGF- $\beta$-dependent mechanism [50]. The aforementioned positive feedback further tilts the balance of tumor immune microenvironment toward a suppressive manner. Breg cell is also identified to be enhanced by MDSC, which is conducted by upregulating IL-10 or downregulating IFN- $\gamma$ in Breg cell under the impact of MDSC [51]. Breg function is also promoted by glioblastoma-associated MDSCs via delivering microvesicles transporting membrane-bound PD-L 1[52] (Fig 4).

CD8+ T-cell-induced immune activity is one major event in the immune attack against tumors. Therefore, the suppression of CD8+ T cell is one of the dominating characteristics of MDSC in tumor microenvironment. ROS production is a major mechanism of MDSC induced CD8+ T cell blunting [53] and PMN-MDSC has been identified as the highest ROS producer in advanced cancer [54]. Nitric oxide (NO) released by MDSC is another key substance that leads to $\mathrm{T}$ cell suppression, which blocks the phosphorylation of downstream 
effectors of IL-2/IL-2R, such as JAK1, JAK3, STAT5, and ERK [55]. Researchers have identified that $M$ MDSC is the massive producer of NO, via regulating the IFN- $\gamma /$ STAT1 pathway [56]. Besides, the decrease in the number of CD8+ T cells can also be induced by MDSC in a possible perforin- and granzyme-dependent manner [57]. Potential amino acid starvation, mainly L-arginine, as the consequence of the upregulated activity of iNOS and arginase- 1 in MDSC might also promote the inhibition of CD8+ T cells [58].

On the other hand, MDSC launch attacks, via expressing or secreting immunosuppressive factors, on pro- inflammatory cells. In breast cancer, IL-6 induces IDO production in MDSC by inhibiting the suppressor of cytokine signaling 3 (SOCS3), and inducing subsequent activation of the JAK/STAT signaling pathway [59]. ROS production in MDSC is identified controlled by proinflammatory NF- $\mathrm{KB}$ heterodimers/immunosuppressive NF- $k B$ homodimers in the nucleus [60]. By augmentation of IDO, NO, and ROS secretion, MDSC can inhibit proliferation and function of $\mathrm{CD} 4^{+} \mathrm{T}$ cells $[18,61,62]$. Previous research has proposed that adenosine can be produced by ectonucleotidases CD39/CD73 on the surface of MDSC [63], and adenosine is identified to
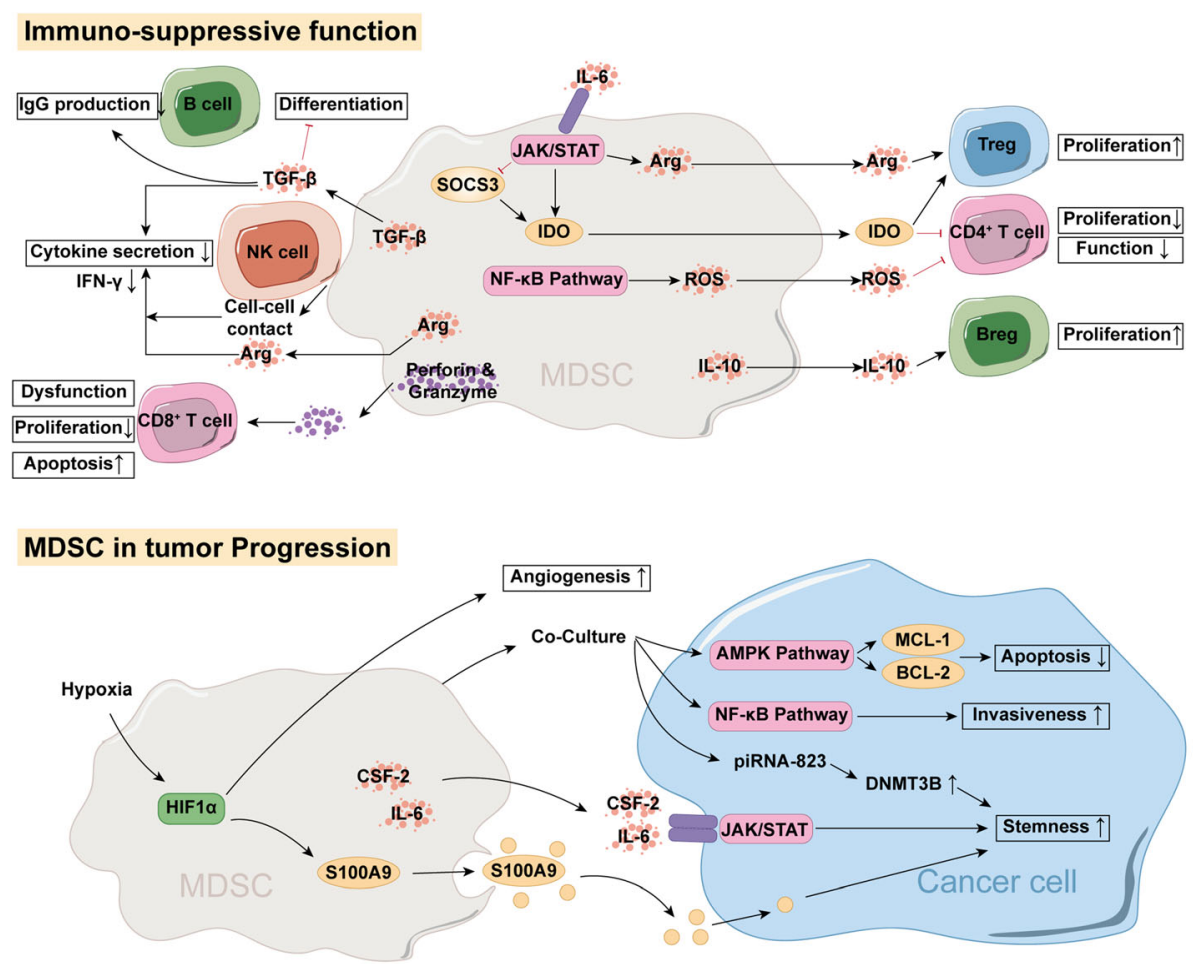

MDSC in tumor metastasis

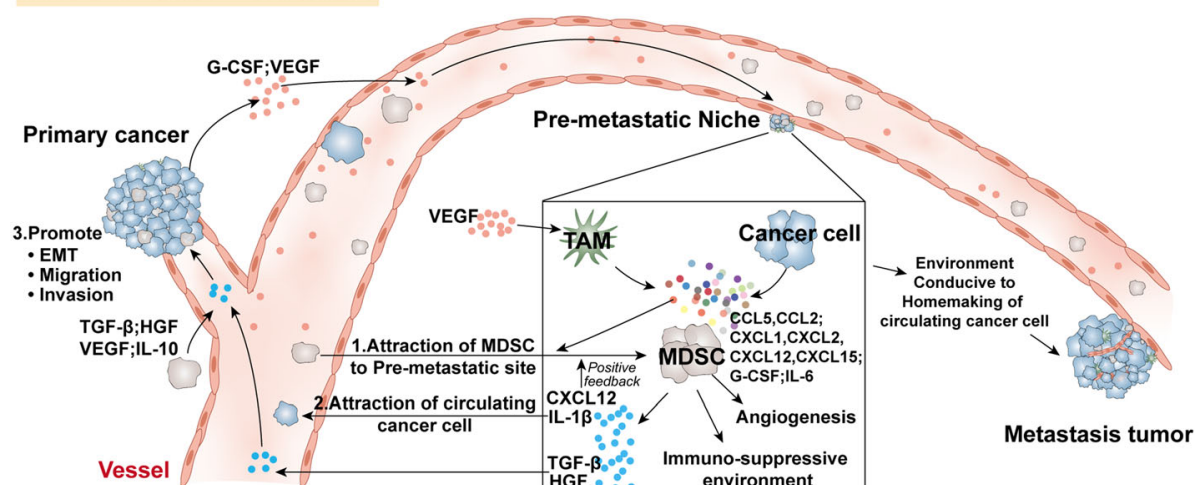

Fig. 4 Characteristics of MDSC in tumor context. Abbreviations: MDSC, Myeloid-derived suppressor cell; NK cell, Natural killer cell; Treg cell, Regulatory T cell; Breg cell, Regulatory B cell; TAM, Tumor-associated macrophages; VEGF, Vascular endothelial growth factor; G-CSF, Granulocyte colony-stimulating factor; EMT, Epithelial-mesenchymal transition 
inhibit $\mathrm{T}$ cell and $\mathrm{NK}$ cell by binding to adenosine A2A receptors (A2AR) on surface of myeloid cells [64]. Additionally, PD-L1 and VISTA inhibit $\mathrm{T}$ cell function under hypoxia [65, 66]. In response to IL-6, differentiation of $\mathrm{CD}_{4}^{+} \mathrm{T}$ cells to Th1 cells is suppressed by MDSC [67]. MDSC can cripple NK cell function and reduce the production of IFN- $\gamma$ in NK cells, through cell-to-cell contact, arginine consumption, and secretion of TGF- $\beta$ [68-70]. B cell differentiation and IgG production are also impaired by TGF$\beta$ under the impact of MDSC [71].

\section{Non-immunological functions of MDSC Functions of MDSC in carcinogenesis}

Previous researches have revealed certain involvement of MDSC in tumorigenesis. As a result of their significant immunosuppressive feature, MDSC recruitment and expansion play great roles in inflammation-associated cancers.

Loss of RNF20, an E3 ligase, along with H2Bub1 reduction is correlated to chronic colonic inflammation and inflammation-associated cancer in an NF-kB dependent manner, which is commonly seen in colorectal cancer genesis. A pro-tumoral microenvironment is created by H2Bub1 reduction, which is partially contributed by augmented immunosuppression via increased MDSC recruitment and activation [72]. The adaptor protein CARD9, a key mediator of innate immunity and expressed on the surface of macrophage [73], is reported to drive transcription of $\mathrm{NF}-\mathrm{KB}$ target genes to launch an immune attack after recognizing fungi in the colon. However, the lack of CARD9 is identified to enhance susceptibility to colitis and colitis-associated colon cancer, due to the impaired fungi-neutralizing function of macrophages that leads to the increased accumulation of MDSC [74]. Another study revealed that early-life exposure to microbiota can induce microbial enduring and host changes that lead to colitis-associated cancer susceptibility, during which enhanced expression of CXCL1, CXCL2, and CXCL5 attracts G-MDSC to generate an immunosuppressive environment [75]. IL-10 secreted by MDSC can inhibit IRF8 expression by upregulating pSTAT3-Dnmt1/3b in colon epithelial cells, which promotes the transformation of normal epithelial cells into cancer cells [76]. Another study described a receptor-interacting protein kinase 3 (RIPK3)-PGE2 signaling circuit in the colorectal tumor microenvironment, which produces PGE2 in a self-amplified manner through NF- $\mathrm{kB}$ signaling in MDSC. The accumulation of MDSC and their immunosuppressive activity contributes to colorectal carcinogenesis [77]. Besides, the absence of Protease-activated receptor 2 (PAR2) in MDSCs is found to directly enhance the immunosuppressive activity of MDSC by promoting
STAT3-mediated ROS production, which also contributes to colorectal carcinogenesis [78]. Porphyromonas gingivalis infection is commonly considered an important factor in triggering oral squamous cell carcinoma (OSCC). In which, chemokines and cytokines including CXCL2, CCL2, IL-6, and IL-8 are found to be upregulated when human-derived dysplastic oral keratinocytes are exposed to P.gingivalis. MDSC is therefore aggregated and activated to generate an immunosuppressive environment that contributes to OSCC genesis [79]. Likewise, MDSC has been identified as an important participant in colitis-related colorectal tumorigenesis [22, 80]. A similar observation has been reported in cholangiocarcinoma research, in which CXCL1 expression in hepatocytes is stimulated by lipopolysaccharides of Gram-negative bacteria through a TLR4-dependent mechanism, leading to the accumulation of $\mathrm{CXCR2}^{+}$PMN-MDSC and drives carcinogenesis [81].

Except for inflammation-associated cancers, MDSC is also reported to have a role in hematologic tumorigenesis. MDSC is found to drive bone marrow hematopoietic abnormalities, manifesting as multilineage cytopenias and cytological dysplasia. An increasing in the secretion of IL10 and TGF- $\beta$ by MDSC is induced by the S100A9-CD33 interaction with myeloid cells, which promotes the formation of multiple myeloma [82]. Favoring the formation of multiple myeloma, the mechanism of which has an impact on the activation of the S100A9-CD33-IL-10/TGF- $\beta$ axis.

\section{Functions of MDSC in cancer progression}

Cancer progression can be regulated from different aspects, MDSC in cancer context is identified to promote cancer cell stemness, proliferation, survival, angiogenesis and invasiveness.

G-MDSC promotes the stemness and growth of CRC cells by secreting exosomes that highly express S100A9. Hypoxia also accelerates CRC progression by increasing S100A9 exosome synthesis in G-MDSC mediated by HIF-1 $\alpha[83]$. In epithelial ovarian cancer (EOC), MDSC is reported to promote EOC cell stemness, which is achieved by activating colony-stimulating factor 2 (CSF2)/p-STAT3 signaling in EOC cells co-cultured with MDSC [84]. In an in vivo model, IL-6 secretion from MDSC endows cancer cell stem-cell-like properties by activating the IL-6/STAT3 signaling pathway [85]. In multiple myeloma (MM), cancer stemness has also been shown to be enhanced by MDSC in an epigenetic manner, that piRNA-823 expression in MDSC promotes DNA methylation [86]. MDSC induces the upregulation of anti-apoptotic factors MCL-1 and BCL-2 and the autophagy-marker LC3II by activating AMPK in MM cells to contribute to the survival of MM cells. Adenosine catalyzed by CD73 on MDSC can promote 
angiogenic factor production in colon cancer [87]. MDSC also accelerates the progression of papillary thyroid carcinoma (PTC) by inhibiting miR-486-3p in PTC cells. Thereby, activated NF-kB2, the direct target of miR-486-3p, promotes invasiveness of PTC cells when co-cultured with PMN-MDSC [88].

\section{Functions of MDSC in tumor metastasis}

Current researches reveal that MDSC plays a vital role in metastasis of various types of cancers. The abundance of MDSC in the peripheral blood is observed to positively correlated with brain metastasis of lung cancer [89]. MDSC-targeting therapy based on the surgical resection of primary breast cancer can significantly reduce lung metastasis of breast cancer cells [90]. One study exploring feasible conditions for tumor metastasis has described a physical cluster in blood, consisting of PMNMDSC and circulating cancer cells are favorable for metastasis, which depends on the generation of ROS in PMN-MDSC [91].

There is one universally accepted mechanism, of promoting cancer metastasis by MDSC, that circulating MDSCs are chemoattracted to pre-metastatic organs by cancer-derived factors diffused in pre-metastatic sites. MDSCs then promote cancer metastasis by creating an environment conducive to the homemaking of circulating cancer cells in the pre-metastatic niche [92-95]. In a liver metastasis model of CRC, it was observed that cancer cells upregulate the secretion of CXCL1 in TAMs in a VEGF dependent manner, which thereby attracts CXCR2-positive MDSCs to form a pre-metastatic niche in the liver to promote the metastasis of colorectal cancer cells [92]. For a lung metastasis model of breast cancer, researchers have found that breast cancer cells promote GPR35+MDSC colonization in the lung by secreting CXCL17 and G-CSF. A reciprocation happens when colonized MDSCs begin to secrete plateletderived growth factor-BB (PDGF-BB), which promotes angiogenesis and colonization of breast cancer cells [94]. Another study has reported that G-CSF secreted by breast cancer cells promotes aggregation of MDSC to pre-metastatic sites [95]. Triple-negative breast cancer (TNBC) is a highly aggressive malignant tumor. Metastasis of TNBC cells is correlated with the high expression of transcription factor $\Delta \mathrm{Np} 63$, which promotes the upregulation of chemokines CXCL2 and CCL22. These chemokines then attract CXCR2/CCR $4^{+}$MDSC to premetastatic niche, and MDSC in turn secretes the pro-metastatic factors MMP9 and chitinase 3-like protein 1 (CHI3L1) to promote TNBC cell metastasis [96]. Spingosine-1-phosphate receptor 1 (S1PR1) in CRC cells activates the STAT3 signaling pathway to induce the production of IL-6, and elevated IL-6 expression is found to promotes MDSC to form a pre-metastatic niche in the liver [97]. A recent study has shown enhanced MDSC recruitment into the pre-metastatic site in the lung in a lactoferrin-knockout mice model, which subsequently leads to significant metastasis of melanoma cells. In this model, TLR9 signaling in MDSC is remarkably attenuated, indicating one possible lactoferrin-TLR9 signaling axis in MDSC that regulates their migration to pre-metastatic organs [98]. Expression of MM9 and IL-1 $\beta$ from MDSC in the premetastatic niche of lungs has a key role in attracting circulating cancer cells $[99,100]$.

Enhanced EMT in cancer cells is also one important mechanism of metastasis, in which MDSC has been identified to be a key mediator. In a melanoma mouse model, the hepatocyte growth factor (HGF) and TGF- $\beta 1$ secreted by PMN-MDSC have been revealed to play a considerable role in inducing EMT in cancer cells of primary site [101]. Another study recently reported that MDSC in breast cancer microenvironment could promote EMT, migration, and invasion of breast cancer cells by activating the PI3K-Akt-mTOR pathway [102]. Strengthened infiltration of MDSC in the breast cancer microenvironment after surgical resection is been observed. The infiltrating MDSC induces EMT of cancer cells by upregulating TGF- $\beta 1$, VEGF and IL- 10 , thus promoting cancer metastasis to the lungs after surgery [103].

A recent study showed that cancer-educated bone marrow mesenchymal stem cells (BMSCs) do not only attract cancer cells into the circulation for distant metastasis via CXCL5/CXCR2 but also induce bone marrowderived PMN-MDSCs. These myeloid-derived PMNMDSCs help cancer cell survival in the distant site, indicating one possible synergistic effect of BMSCs and MDSC in tumor metastasis [104]. G protein-coupled receptor family $\mathrm{C}$ group 5 type A (GPRC5A) is a lung cancer suppressor gene. MDSC number is revealed to abnormally increase in lung cancer in a Gprc5aknockout mouse model, which promotes lung cancer metastasis regulated by enhanced prostaglandin E synthase (PTGES)/PGE2 signaling [105]. IL-6 upregulation in Gprc5a-knockout mice is identified to explain the promoted metastasis of cancer, in which IL-6 activates the STAT3 signaling pathway and induces the recruitment of MDSC to promote lung metastasis [106]. A study on microsomal prostaglandin $E$ synthase-1 (mPGES-1) discovered that host stromal mPGES-1induced PGE2 upregulates SDF-1 in a murine model of lung metastasis from prostate cancer. SDF-1 in the microenvironment upregulates CCR4+MDSC infiltration in the lung, and accumulated MDSC in turns secrete more SDF-1 to form a positive feedback, which promotes the metastasis of CCR4+ prostate cancer cells [107]. Vashibin-2 (vash2) expressed in pancreatic ductal 
adenocarcinoma (PDAC) can induce MDSC attraction by secreting chemokines including CXCL2, CXCL5, CCL2, and CCL5, which promotes angiogenesis and metastasis [108]. In a mouse model of lung adenocarcinoma, signal transduction by TLR7 on the surface of cancer cells can also recruit MDSCs to promote cancer progression and metastasis [109].

\section{MDSC in cancer therapy}

\section{MDSC and prognosis of cancers}

In recent years, enormous efforts have been made in the exploration of the prognostic value of MDSC in various cancers. We, therefore, provide a comprehensive review of the current progress on assessing the prognostic significance of MDSC in 13 human cancers (Fig 5, Supplementary Tables 1 and 2).

\section{Total-MDSC}

The association of circulating total MDSC in the peripheral blood with disease free survival (DFS) and/or overall survival (OS) has been voluminously reported in cancers with different histology and origin, including pancreatic cancer [110], esophageal squamous cell carcinoma (ESCC )[110], gastric cancer [110, 111], CRC [112-114], HCC [115-117], breast cancer [114], NK/T lymphoma [118], and melanoma $[119,120]$. The negative association of peripheral MDSC and clinical outcomes was built in over 700 patients across eight solid cancer types. A notable exception was also emerged for gastric cancer from a 40patients cohort, in which the frequency of Lin $^{-}$HLA$\mathrm{DR}^{-} \mathrm{CD} 33^{+}$MDSC was not a prognosis indicating factor of late-stage cancer [111]. HLA-DR ${ }^{-} \mathrm{Lin}^{\text {low/- }} \mathrm{CD} 33^{+}$ $\mathrm{CD}_{11} \mathrm{~b}^{+}$label is commonly used for total MDSC recognition in these cancers. An unusual phenotype, HLA$\mathrm{DR}^{-} \mathrm{CD} 33^{\text {low }} \mathrm{CD} 11 \mathrm{~b}^{+} \mathrm{CD}^{-}$MDSC, was demonstrated in bladder cancer, the presence of which in the peripheral blood was reported as a significant factor for poor prognosis factor [121]. However, more covariates, such as histological subsets of tumors and the cut-off value of MDSC frequency, should to be taken into consideration in evaluating the prognostic value in these cancers to make the conclusion more solid. It remains to be further evaluated whether the frequency of total MDSC is an independent prognostic factor. Maybe a customized systematic regression model of multiple-factors in a study of individual cancer types is a preferred solution for further evaluation. Nonetheless, an association of a high frequency of circulating MDSC and poor clinical outcomes has been discovered in these tumors.

\section{MDSC subsets}

M-MDSC and PMN-MDSC populations are commonly recognized as $\mathrm{CD} 14^{+} \mathrm{CD} 15^{-}$and $\mathrm{CD} 14^{-} \mathrm{CD} 15^{+}$phenotypes, respectively. Explorations on the prognostic value of M-MDSC in clinical studies have found that peripheral presence is a significant predicting factor of patients' outcomes. Higher amount of circulating M-MDSC has been demonstrated as a significant prognosis indicator in renal cell carcinoma (RCC )[14], HCC [122, 123], prostate cancer [124], ESCC [125], NK/T lymphoma [118], and melanoma [126-130]. There is also controversy in studies on lung cancer that frequency of $\mathrm{M}$ MDSC was proposed as an effective prognosis indicator in small cell and non-small cell lung cancer (NSCLC )[131, 132]. However, researchers have also reported non-significant results upon evaluating the prognostic value of M-MDSC amount in NSCLC [16, 133]. Besides, research on head and neck squamous cell carcinoma (HNSCC), pancreatic cancer, breast cancer, and gastric cancer have demonstrated that M-MDSC may not be a prognostic marker in these tumors [134-137]. As for prognostic value in PMN-MDSC, it seems that no consensus has been reached. Researchers have claimed that frequency of peripheral PMN-MDSC can be an effective prognosis indicator in gastric cancer [111, 138], breast cancer [139], HNSCC [134],RCC [140], and prostate cancer [141]. The same evidence has been demonstrated in NSCLC [132], and pancreatic cancer [142], while non-supportive evidence has also been reported [16, 135]. Interestingly, an unusual phenotype of CD14+ CD15+ MDSC has been discovered in one study on NSCLC, in which a higher frequency of CD14+CD15+ MDSC was associated with forlorn prognosis [16]. Generally, a short take-home message here is the requirement of further detailed studies with a larger sample size and customized covariates enrolled assessment model in individual cancer types. The cut-off value used for distinguishing high or low frequency of MDSC is another key covariate. However, no consensus at present has been reached regarding whether there is a definite cutoff value.

\section{MDSC and response of immunotherapies}

Immunotherapy is becoming one of the leading edges and new hope in cancer treatment. By enhancing $\mathrm{T}$ cellmediated cytotoxicity attack or recovering dysfunctional $\mathrm{T}$ cell, agents that reboot the immune activity in the cancer microenvironment has shown certain therapeutic effect in several cancers [143, 144]. Tumor killing activity is induced via two mechanisms by $\mathrm{T}$ cells. One is upon antigen-specific signal by $\mathrm{T}$ cell receptors recognition [145]. Another one is generated upon an antigenindependent signal regulated by co-signaling receptors, for which PD-1 and CTLA-4 are crucial co-inhibitors [146]. CTLA-4 promotes immunosuppression by competitively diminishing the co-stimulatory effect of CD2 8[147]. Therefore, CTLA-4 has been developed as a therapeutic target to enhance anti-tumor 


\section{A}

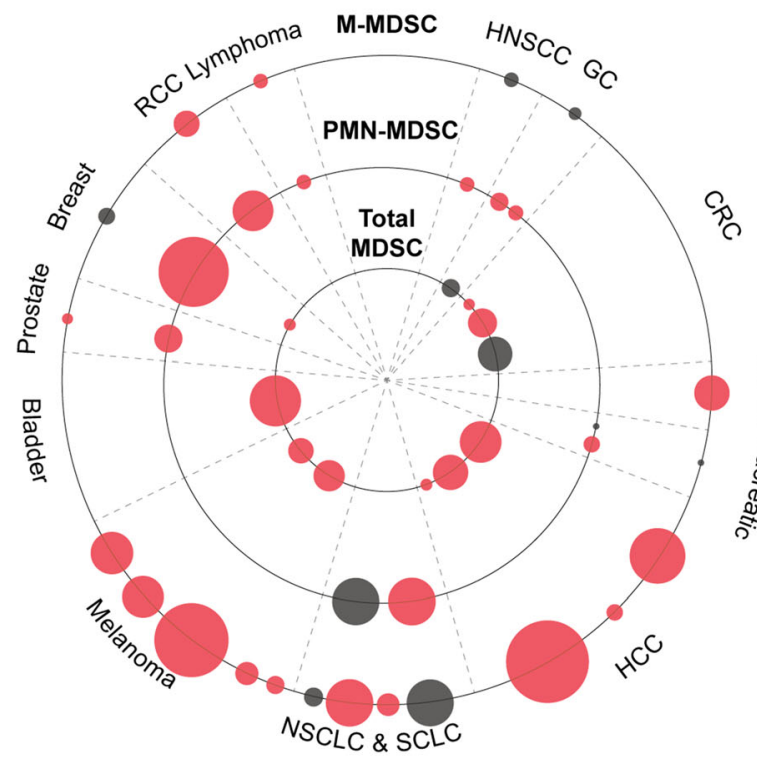

Sample Size

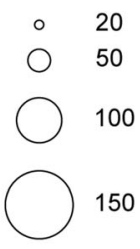

Prognostic Association

Negative

Not Significant

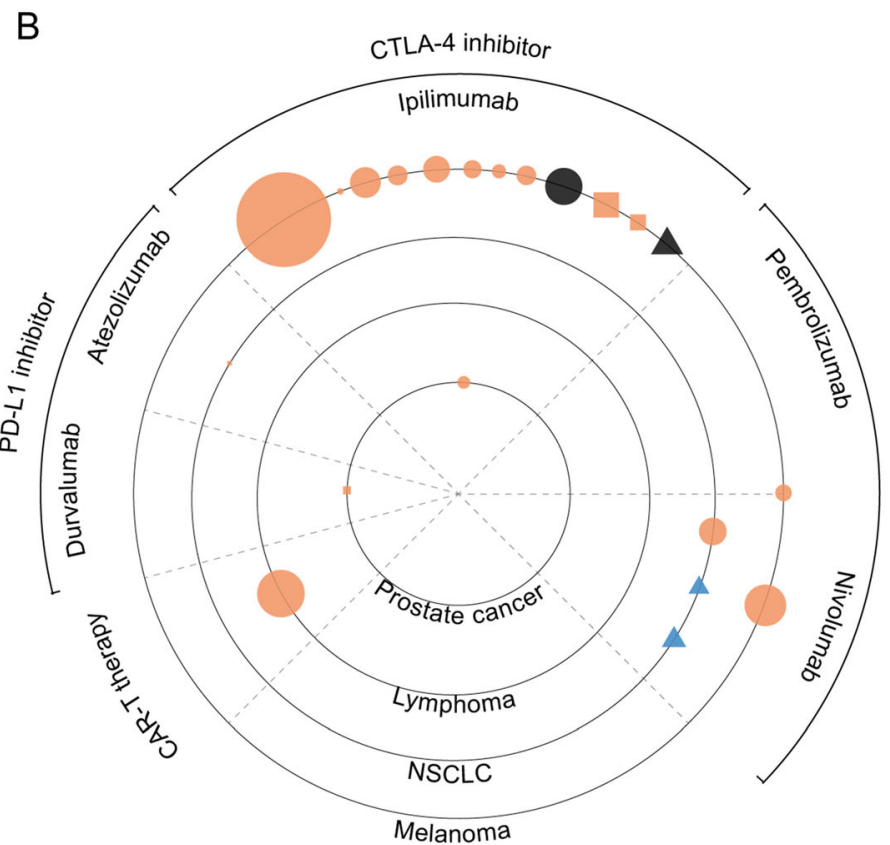

Sample Size

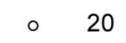

○ 50

○ 100

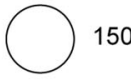

$\overrightarrow{0}$ Response Association

$\overrightarrow{3}$ Negative

굴 Positive

§ै Not significant

MDSC Phenotype

Total-MDSC

M-MDSC

$\triangle P M N-M D S C$

Fig. 5 MDSC as a prognostic factor of tumor treatment. A: Data from studies (Supplementary Table 1) involving patients across cancer types displayed were analyzed regarding the relevance of MDSC and the prognoses of cancer patients receiving anti-tumor therapy. Each circle represents a study and the size of the circle is proportional to the number of the patients involved. The association of the MDSC level and the prognoses of cancer patients is demonstrated as red (negative correlation) or grey (no significant correlation); B: Data from studies (Supplementary Table 2) involving patients across cancer types displayed were analyzed regarding the relevance of MDSC and the response of cancer patients receiving immune-checkpoint inhibitors. Square represents total MDSC, circle represents M-MDSC, and triangle represents PMN-MDSC. Each square/circle/triangle represents a study and the size is proportional to the number of the patients involved. The association of the MDSC level and the response of ICI treatment is demonstrated as orange (negative correlation), blue (positive correlation), and deep grey (no significant correlation). Abbreviations: MDSC, Myeloid-derived suppressor cell; M-MDSC, Monocytic MDSC; PMN-MDSC, Polymorphonuclear MDSC; HNSCC, Head and neck squamous cell carcinoma; GC, Gastric carcinoma; CRC, Colorectal cancer; ESCC, Esophageal squamous cell carcinoma; HCC, Hepatocellular carcinoma; NSCLC, Non-small cell lung cancer; SCLC, Small cell lung cancer; RCC, Renal cell carcinoma 
immunoactivity, and the monoclonal antibody, ipilimumab, is the first and only FDA-approved inhibitor in cancer treatment.

The interaction of programmed death 1 (PD-1) and its ligand PD-L1 are involved in another important immune inhibitory process, which leads to $\mathrm{T}$ effector cell exhaustion and their conversion into Tregs [148]. Blockade of PD-1/PD-L1 signaling can enhance anti-tumor immunoactivity of $\mathrm{T}$ cells.

Accumulating evidence have shown that MDSC can significantly affect the patient response of immunotherapy.

\section{CTLA-4 inhibitor}

Ipilimumab (Yervoy) is a human cytotoxic T-lymphocyte antigen 4 (CTLA-4) monoclonal antibody that has been approved by FDA for treating late-stage melanoma in 2011 [149]. In advanced melanoma, several clinical studies have shown that a low frequency of peripheral CD14 ${ }^{+}$MDSC in patients is significantly associated with OS and ipilimumab response. Frequency of MDSC has been proposed to be an independent predictor factor of OS in late-stage melanoma. Another study of ipilimumab plus GVAX tumor vaccine treatment in castrationresistant prostate cancer showed similar result that high frequency of $\mathrm{CD} 14^{+}$MDSC is correlated with shorten OS.

\section{PD-1 inhibitor}

PD-1 and its ligands, PD-L1 (also known as B7-H1) and PD-L2 (also known as B7-H2), are critical inhibitory mediators of the tumor microenvironment. PD-1 serves as a transmembrane protein and is mainly expressed on several immune cells, including $\mathrm{T}$ cells, B cells, NKs, and MDSCs. PD-L1 is widely-expressed on various cell including tumor cells and hematopoietic cells, while PD-L2 expression is restricted to hematopoietic cells. PD-1-PD-L1/ 2 interaction is a key mechanism in tumor immune evasion. Blocking PD-1 or PD-L1/2 is an important strategy to regulate the tumor immune microenvironment, enhance anti-neoplastic activity, and kill tumor cells. Up to now, there are three PD-1 inhibitors approved by FDA, including pembrolizumab, nivolumab, and cemiplimab.

Nivolumab (Opdivo) is the first human IgG4 monoclonal PD-1 antibody. Based on CheckMate-037, it was first approved by FDA in December, 201 4[150]. So far, multiple indications of nivolumab in solid cancers have been approved by FDA.

Pembrolizumab (Keytruda) is another human IgG monoclonal antibody, firstly approved by FDA based on the clinical trial KEYNOTE-001 in September 2014. Pembrolizumab is now approved for indications in multiple solid cancers, including melanoma, NSCLC, SCLC, HNSCC, etc. Pembrolizumab was also approved for patients with unresectable or metastatic, microsatellite instability-high (MSI-H) or mismatch repair deficient cancers.

Cemiplimab (Libtayo) is the third human IgG4 monoclonal PD-1 antibody approved by FDA in September 2018. Cemiplimab is now indicated for the treatment of patients with metastatic cutaneous squamous cell carcinoma (CSCC) or the ones with locally advanced CSCC who are not candidates for curative surgery or radiation.

Various researchers have investigated whether MDSC could predict the clinical response and survival for patients receiving PD-1 inhibitors. Several studies have demonstrated that M-MDSC may be inversely correlated with the clinical benefit of PD-1 inhibitors. In a study that enrolled 36 patients with advanced melanoma who were undergoing nivolumab or pembrolizumab treatment, patients with higher frequencies of M-MDSC at the baseline and after the first treatment cycle had worse OS [151]. Another study of 61 metastatic non-small cell lung cancer patients also supports that high levels of blood M-MDSC have a negative impact on anti-PD-1 efficacy [152]. A similar conclusion was also obtained from a clinical trial including 92 ipilimumab-refractory patients with unresectable stage III or IV melanoma [129].

However, when it comes to G-MDSC, the result seems to be the opposite. In a cohort of 53 patients with NSCLC, higher baseline levels of G-MDSC were associated with a significantly better response of nivolumab treatment [153]. After the first treatment of nivolumab, the median percentage of Lox-1+ G-MDSCs in the responders was higher than that in the non-responders [154].

\section{PD-L1 inhibitor}

PD-L1 inhibitors have also been developed as a target of immunotherapy. Atezolizumab (Tecentriq) is a PD-L1 monoclonal antibody that was first approved for the administration of advanced or metastatic urothelial bladder cancer according to the results of the clinical trial IMvigor 210 (NCT02108652). Durvalumab (Imfinzi) is another anti-PD-L1 agent that has been approved by FDA to treat urothelial cancer according to the results of NCT01693562. Avelumab (Bavencio), also a PD-L1 inhibitor, has been approved for the management of Merkel cell carcinoma as the evidence of the clinical trial JAVELIN Merkel 200 (NCT 02155647).

Researchers have noticed that frequency of $\mathrm{Lin}^{-}$HLA$\mathrm{DR}^{\text {low/- }} \mathrm{CD}_{11 \mathrm{~b}^{+}} \mathrm{CD}^{+} 3^{+}$total MDSC is associated with the response of atezolizumab in patients with advanced NSCLC. Lower total MDSC in the peripheral blood of patients is correlated with better outcomes. However, the cohort had a relatively small sample size of merely ten [155]. A similar result has been demonstrated in a study of durvalumab, in which lower frequency of HLA$\mathrm{DR}^{-} \mathrm{CD} 11 \mathrm{~b}^{+} \mathrm{CD}_{3}{ }^{+}$total MDSC in the peripheral blood of patients with metastatic castration-resistant prostate 
cancer was associated with better response of durvalumab plus PARP inhibitor olaparib administration [156].

\section{Briefing of MDSC impact on immunotherapy}

Evaluations on the prognostic value of MDSC in various cancer types have provided plenty of evidence that the frequency of peripheral MDSC can be a good indicator of clinical response of immunotherapy. A higher level of circulating total MDSC, recognized as $\mathrm{Lin}^{-} \mathrm{HLA}^{-}$ $\mathrm{DR}^{\text {low/- }} \mathrm{CD} 11 \mathrm{~b}^{+} \mathrm{CD}_{3}{ }^{+}$population, has been associated with worse response of ipilimumab administration in patients with melanoma. A similar verdict has been presented in prostate cancer and NSCLC, which indicated a high frequency of total MDSC can be an indication of poor response to PD-L1 inhibitor, however, in relatively small cohorts. The vast majority of studies on MDSC have been performed in melanoma patients with ipilimumab administration. As summarized above, a significant association has been built that higher frequency of circulating M-MDSC in patients with melanoma and their poor ipilimumab response, as well as worse prognosis. A similar verdict has been proposed in a study of patients with castration-resistant prostate cancer administrated with ipilimumab plus tumor vaccine treatment [124]. Besides, other pieces of evidence also support the prognostic value of circulating M-MDSC in predicting the response of PD-1 inhibitors in melanoma and NSCLC. Interestingly, the same verdict has been mentioned in a study of refractory/relapsed large B lymphoma treated with CAR-T therapy (Axicabtagene ciloleucel) where high blood levels of M-MDSC, IL-6, and ferritin were associated with a lack of durable response to treatment [157]. On the other hand, a higher level of the peripheral PMN-MDSC has been demonstrated to corelated with a preferable response of nivolumab in patients with NSCL C. Overall, circulating MDSC has been proposed as a well-performed predicting factor of prognosis and the response of immunotherapies in various cancer types, however, detailed research of larger sample size that is customized to individual cancer types is still required for further validation. Additionally, evaluations of the prognostic value of MDSC and its subsets in cancers administrated with other immune-checkpoint inhibitors (ICIs), such as TIM-3, LAG-3, and TIGIT inhibitors, have not been performed or mentioned so far, which is quite crucial and urgent.

\section{Targeting MDSC in tumor therapy}

\section{Targeting key molecules of MDSC}

In this systematic review, we summarized several key molecules related to MDSC activity in the tumor microenvironment that play multiple or vital roles in MDSCinfiltrated tumor microenvironment. These key molecules may serve as potential targets of MDSC inhibition that are suitable for combination with immunotherapies (Table 1).

\section{CXCR2 \& CXCR4}

CXCR2, also known as interleukin 8 receptor beta (IL8RB), is a member of the G protein-coupled receptor family that canonically binds to IL-8. CXCR2 is a key mediator of MDSC recruitment by directly binding to CXCL1, CXCL2, CXCL3, and CXCL 5[22-25, 37]. CXCR4, also known as fusin or CD184, has been identified as another important mediator of MDSC recruitment regulated by the autocrine of PGE2 and TGF- $\beta$ $[35,39]$. A combination of CXCR4 antagonist and IDO1 inhibitor was demonstrated to diminish MDSC and delay the progression of metastatic breast cancer in an in vivo mice model [158]. MDSC was reported to participant in tumor metastatic in a pre-metastatic niche pattern, in which MDSC can attract tumor cells via CXCL5/CXCR2 interaction [104]. Another research showed that low-dose DNA methyltransferase and histone deacetylase inhibitors, 5-azacytidine and entinostat, reduce the transportation of MDSCs into the premetastatic niche by impairing the expression of CCR2 and CXCR2, which promotes the differentiation of MDSCs into a more-interstitial macrophage-like phenotype to destroy the pre-metastatic niche formation that favors cancer cell metastasis [159]. CXCR2/4 activity may be one major mediator in MDSC recruitment and MDSC related tumor metastasis. From the perspective of clinical view, several early-stage clinical trials of CXCR2 and CXCR4 antagonists combined with ICIs have been registered. Among them, reparixin, SX-682, and AZD5069 are three on course CXCR2 inhibitors undergoing clinical trials of ICI-combined therapies in tumor administration. One phase Ib/II study of durvalumab plus AZD5069 in metastatic pancreatic ductal carcinoma (PDAC) reported a $1 / 18$ ORR rate (NCT02583477). Two CXCR4 inhibiting agents, plerixafor and motixafortide (BL-8040), have been registered in two and three clinical trials respectively, however, no results have been posted at present.

\section{Toll like receptors}

Toll-like receptors (TLRs) are a class of proteins that play a key role in the innate immune response that are canonically expressed on sentinel cells such as macrophages and dendritic cells. TLR4 is reported to have a role in generating PD-L1+ immunosuppressive MDSC in melanoma an in vivo model [160]. MDSC expansion is reported to regulated by exosome mediated TLR2/ MyD88 signaling [161]. TLR7 and TLR9 are proposed to play a role in the migration of MDSC to pre-metastatic organs [98, 109]. However, no evidence has emerged to 
Table 1 Detailed information of the combination therapy of $\mathrm{ICl}$ and inhibitors of key molecules.

\begin{tabular}{|c|c|c|c|c|c|c|}
\hline Drug & NCT No. & Tumor & Phase & Status & Therapy & Conclusion \\
\hline \multicolumn{7}{|l|}{ Anti- CXCR2 } \\
\hline Reparixin & NCT02001974 & $\begin{array}{l}\text { HER } 2 \text { Negative Metastatic } \\
\text { Breast Cancer }\end{array}$ & 1 & Completed & Paclitaxel+Reparixin & / \\
\hline Reparixin & NCT01861054 & Early Breast Cancer & $\|$ & Terminated & Reparixin & / \\
\hline SX-682 & NCT03161431 & Metastatic Melanoma & । & Recruiting & SX-682 + Pembrolizumab & / \\
\hline SX-682 & NCT04477343 & $\begin{array}{l}\text { Metastatic Pancreatic Ductal } \\
\text { Adenocarcinoma }\end{array}$ & I & Recruiting & SX-682 + Nivolumab & / \\
\hline SX-682 & NCT04574583 & Advanced Solid Tumors & $|/| \mid$ & Recruiting & SX-682 + M7824 + CV301 & / \\
\hline SX-682 & NCT04599140 & $\begin{array}{l}\text { RAS-Mutated, MSS Unresectable } \\
\text { or Metastatic Colorectal Cancer }\end{array}$ & $|/| \mid$ & Recruiting & SX-682 + Nivolumab & / \\
\hline AZD5069 & NCT02583477 & $\begin{array}{l}\text { Metastatic Pancreatic Ductal } \\
\text { Carcinoma }\end{array}$ & $|/| \mid$ & Completed & MEDI4736 + AZD5069 & $\begin{array}{l}\text { 1/18 ORR } \\
\text { (durvalumab + } \\
\text { CXCR1/2 } \\
\text { inhibitor) }\end{array}$ \\
\hline AZD5069 & NCT02499328 & $\begin{array}{l}\text { Advanced Solid Tumors \& } \\
\text { Relapsed Metastatic Squamous } \\
\text { Cell Carcinoma of Head \& Neck }\end{array}$ & $\|$ & $\begin{array}{l}\text { Active, not } \\
\text { recruiting }\end{array}$ & MEDI4736 + AZD5069 & / \\
\hline \multicolumn{7}{|l|}{ Anti-CXCR4 } \\
\hline Plerixafor & NCT04177810 & Metastatic Pancreatic Cancer & $\|$ & Recruiting & Cemiplimab + Plerixafor & / \\
\hline Plerixafor & NCT04058145 & $\begin{array}{l}\text { Refractory Head and Neck } \\
\text { Squamous Cell Carcinoma }\end{array}$ & $\|$ & Withdrawn & Pembrolizumab+AMD3100 & / \\
\hline Plerixafor & NCT03240861 & Advanced Cancer & । & Recruiting & $\begin{array}{l}\text { Aldesleuki + Busulfan + LV-NYESO TCR + } \\
\text { sr39TK PBSC IV and RV-NYESO TCR PBMC } \\
\text { IV + Filgrastim + Fludarabine + Plerixafor }\end{array}$ & / \\
\hline $\begin{array}{l}\text { Motixafortide } \\
\text { (BL-8040) }\end{array}$ & NCT02826486 & $\begin{array}{l}\text { Metastatic Pancreatic } \\
\text { Adenocarcinoma }\end{array}$ & $\|$ & $\begin{array}{l}\text { Active, not } \\
\text { recruiting }\end{array}$ & $\begin{array}{l}\text { BL-8040 + Pembrolizumab; BL-8040 + } \\
\text { Pembrolizumab + Onivyde }\end{array}$ & / \\
\hline $\begin{array}{l}\text { Motixafortide } \\
\text { (BL-8040) }\end{array}$ & NCT03154827 & $\begin{array}{l}\text { Acute Myeloid Leukemia Who } \\
\text { Are } 60 \text { Years or Older }\end{array}$ & $|/| \mid$ & Terminated & BL-8040 + Atezolizumab & / \\
\hline $\begin{array}{l}\text { Motixafortide } \\
\text { (BL-8040) }\end{array}$ & NCT02907099 & Metastatic Pancreatic Cancer & $\|$ & $\begin{array}{l}\text { Active, not } \\
\text { recruiting }\end{array}$ & BL-8040 + Pembrolizumab & / \\
\hline $\begin{array}{l}\text { Motixafortide } \\
\text { (BL-8040) }\end{array}$ & NCT03193190 & $\begin{array}{l}\text { Metastatic Pancreatic Ductal } \\
\text { Adenocarcinoma (Morpheus- } \\
\text { Pancreatic Cancer) }\end{array}$ & $|/| \mid$ & Recruiting & Atezolizumab + BL-8040 & / \\
\hline LY2510924 & NCT02737072 & Solid Tumors & । & Terminated & $\begin{array}{l}20 \text { mg LY2510924 + } 1500 \text { mg } \\
\text { Durvalumab; } 30 \text { mg LY2510924 + } 1500 \\
\text { mg Durvalumab; } 40 \text { mg LY2510924 + } \\
1500 \text { mg Durvalumab }\end{array}$ & $\begin{array}{l}\text { 0/3;0/3;0/3 } \\
\text { ORRs in each } \\
\text { arms. } \\
\text { 3/3; } 1 / 3 ; 0 / 3 \\
\text { DCRs in each } \\
\text { arms }\end{array}$ \\
\hline BMS-936564 & NCT02472977 & Solid Tumors & $|/| \mid$ & Terminated & $\begin{array}{l}\text { BMS-936564 (Ulocuplumab) + Nivolumab } \\
\text { (SCLC); BMS-936564 (Ulocuplumab) + } \\
\text { Nivolumab (PAC) }\end{array}$ & $\begin{array}{l}0 / 6 \text { and } 0 / 27 \\
\text { ORRs in PAC. }\end{array}$ \\
\hline \multicolumn{7}{|l|}{ Anti-TGF- $\beta$} \\
\hline ABBV-151 & NCT03821935 & $\begin{array}{l}\text { Locally Advanced or Metastatic } \\
\text { Solid Tumors }\end{array}$ & । & Recruiting & ABBV-151 + Budigalimab & / \\
\hline Pirfenidone & NCT04467723 & Stage IV and recurrent NSCLC & $|/| \mid$ & $\begin{array}{l}\text { Not yet } \\
\text { recruiting }\end{array}$ & Atezolizumab + Pirfenidone & / \\
\hline \multicolumn{7}{|c|}{ Anti-TGF- $\beta(m A b)$} \\
\hline NIS793 & NCT02947165 & Advanced Malignancies & I & $\begin{array}{l}\text { Active, not } \\
\text { recruiting }\end{array}$ & NIS793 + PDR001 & / \\
\hline NIS793 & NCT04390763 & $\begin{array}{l}\text { First-line Metastatic Pancreatic } \\
\text { Ductal Adenocarcinoma }\end{array}$ & $\|$ & Recruiting & $\begin{array}{l}\text { NIS793 + spartalizumab + gemcitabine + } \\
\text { nab-paclitaxel; }\end{array}$ & / \\
\hline SAR439459 & NCT03192345 & Advanced Solid Tumors & । & Recruiting & SAR439459 + cemiplimab & / \\
\hline SAR439459 & NCT04729725 & Advanced or Unresectable Solid & । & Recruiting & SAR439459 + cemiplimab & / \\
\hline
\end{tabular}


Table 1 Detailed information of the combination therapy of $\mathrm{ICl}$ and inhibitors of key molecules. (Continued)

\begin{tabular}{|c|c|c|c|c|c|c|}
\hline Drug & NCT No. & Tumor & Phase & Status & Therapy & Conclusion \\
\hline
\end{tabular}

\section{Anti-TGF- $\beta$ and PD-L1}

\begin{tabular}{|c|c|c|c|c|c|}
\hline $\begin{array}{l}\text { Bintrafusp } \\
\text { alfa (M7824) }\end{array}$ & NCT04633252 & $\begin{array}{l}\text { Metastatic Castration Sensitive } \\
\text { and Castration Resistant Prostate } \\
\text { Cancer }\end{array}$ & $|/| \mid$ & Recruiting & $\begin{array}{l}\text { Docetaxel + M9241; Docetaxel + M9241 + } \\
\text { M7824 }\end{array}$ \\
\hline $\begin{array}{l}\text { Bintrafusp } \\
\text { alfa (M7824) }\end{array}$ & NCT03631706 & $\begin{array}{l}\text { Programmed Death-ligand } 1 \\
\text { (PD-L1) Expressing Advanced } \\
\text { Non-small Cell Lung Cancer } \\
\text { (NSCLC) }\end{array}$ & III & $\begin{array}{l}\text { Active, not } \\
\text { recruiting }\end{array}$ & M7824 + Pembrolizumab \\
\hline $\begin{array}{l}\text { Bintrafusp } \\
\text { alfa (M7824) }\end{array}$ & NCT03840902 & Unresectable Stage III NSCLC & $\|$ & Recruiting & cCRT + M7824 followed by M7824; \\
\hline $\begin{array}{l}\text { Bintrafusp } \\
\text { alfa (M7824) }\end{array}$ & NCT03833661 & $\begin{array}{l}\text { Locally Advanced or Metastatic } \\
\text { Second Line (2L) Biliary Tract } \\
\text { Cancer (Cholangiocarcinoma } \\
\text { and Gallbladder Cancer) }\end{array}$ & $\|$ & $\begin{array}{l}\text { Active, not } \\
\text { recruiting }\end{array}$ & M7824 \\
\hline $\begin{array}{l}\text { Bintrafusp } \\
\text { alfa (M7824) }\end{array}$ & NCT04574583 & Advanced Solid Tumors & $|/| \mid$ & Recruiting & SX-682 + M7824 + CV301 \\
\hline $\begin{array}{l}\text { Bintrafusp } \\
\text { alfa (M7824) }\end{array}$ & NCT03524170 & $\begin{array}{l}\text { Metastatic Hormone Receptor } \\
\text { Positive, HER2 Negative Breast } \\
\text { Cancer }\end{array}$ & I & Recruiting & M7824 + radiation therapy \\
\hline $\begin{array}{l}\text { Bintrafusp } \\
\text { alfa (M7824) }\end{array}$ & NCT03554473 & $\begin{array}{l}\text { Relapsed Small Cell Lung } \\
\text { Cancers }\end{array}$ & $|/| \mid$ & Recruiting & $\begin{array}{l}\text { M7824; } \\
\text { M7824 + Topotecan; } \\
\text { M7824 + Temozolomide }\end{array}$ \\
\hline $\begin{array}{l}\text { Bintrafusp } \\
\text { alfa (M7824) }\end{array}$ & NCT04296942 & $\begin{array}{l}\text { Advanced Stage Breast Cancer } \\
\text { (BrEAsT) }\end{array}$ & । & Recruiting & $\begin{array}{l}\text { M7824 + BN-Brachyury; } \\
\text { M7824 + BN-Brachyury + T-DM1; } \\
\text { M7824 + BN-Brachyury + T-DM1 + } \\
\text { Entinostat }\end{array}$ \\
\hline $\begin{array}{l}\text { Bintrafusp } \\
\text { alfa (M7824) }\end{array}$ & NCT04327986 & Advanced Pancreas Cancer & $|/| \mid$ & $\begin{array}{l}\text { Not yet } \\
\text { recruiting }\end{array}$ & $\begin{array}{l}\text { M9241 + M7824; } \\
\text { M9241 + M7824+ SBRT }\end{array}$ \\
\hline $\begin{array}{l}\text { Bintrafusp } \\
\text { alfa (M7824) }\end{array}$ & NCT04432597 & HPV Associated Cancers & $|/| \mid$ & Recruiting & HPV vaccine + M7824 \\
\hline $\begin{array}{l}\text { Bintrafusp } \\
\text { alfa (M7824) }\end{array}$ & NCT03579472 & $\begin{array}{l}\text { Metastatic Triple Negative Breast } \\
\text { Cancer }\end{array}$ & । & Recruiting & Bintrafusp alfa + eribulin mesylate \\
\hline $\begin{array}{l}\text { Bintrafusp } \\
\text { alfa (M7824) }\end{array}$ & NCT04066491 & 1L Biliary Tract Cancer (BTC) & $\|/\| \|$ & Recruiting & $\begin{array}{l}\text { Bintrafusp alfa + Gemcitabine + Cisplatin; } \\
\text { Bintrafusp alfa + Gemcitabine + Cisplatin }\end{array}$ \\
\hline $\begin{array}{l}\text { Bintrafusp } \\
\text { alfa (M7824) }\end{array}$ & NCT04235777 & $\begin{array}{l}\text { Adults With Metastatic Non- } \\
\text { Prostate Genitourinary } \\
\text { Malignancies }\end{array}$ & । & Recruiting & $\begin{array}{l}\text { M7824 + M9241 if appropriate; } \\
\text { M7824 + M9241 (if appropriate) + } \\
\text { sequential SBRT; } \\
\text { M7824 + M9241 (if appropriate) + } \\
\text { concurrent SBRT }\end{array}$ \\
\hline $\begin{array}{l}\text { Bintrafusp } \\
\text { alfa (M7824) }\end{array}$ & NCT02517398 & $\begin{array}{l}\text { Metastatic or Locally Advanced } \\
\text { Solid Tumors }\end{array}$ & । & $\begin{array}{l}\text { Active, not } \\
\text { recruiting }\end{array}$ & M7824 \\
\hline $\begin{array}{l}\text { Bintrafusp } \\
\text { alfa (M7824) }\end{array}$ & NCT03620201 & $\begin{array}{l}\text { Stage II-III HER2 Positive Breast } \\
\text { Cancer }\end{array}$ & । & Recruiting & M7824 \\
\hline $\begin{array}{l}\text { Bintrafusp } \\
\text { alfa (M7824) }\end{array}$ & NCT02699515 & $\begin{array}{l}\text { Metastatic or Locally Advanced } \\
\text { Solid Tumors }\end{array}$ & I & $\begin{array}{l}\text { Active, not } \\
\text { recruiting }\end{array}$ & M7824 \\
\hline $\begin{array}{l}\text { Bintrafusp } \\
\text { alfa (M7824) }\end{array}$ & NCT04489940 & $\begin{array}{l}\text { High Mobility Group AT-Hook } 2 \\
\text { (HMGA2) Expressing Triple } \\
\text { Negative Breast Cancer }\end{array}$ & $\|$ & Recruiting & M7824 \\
\hline $\begin{array}{l}\text { Bintrafusp } \\
\text { alfa (M7824) }\end{array}$ & NCT03436563 & $\begin{array}{l}\text { Advanced Solid Tumors With } \\
\text { Microsatellite Instability }\end{array}$ & $|/| \mid$ & Recruiting & M7824 \\
\hline $\begin{array}{l}\text { Bintrafusp } \\
\text { alfa (M7824) }\end{array}$ & NCT04246489 & $\begin{array}{l}\text { Platinum-Experienced Cervical } \\
\text { Cancer }\end{array}$ & $\|$ & $\begin{array}{l}\text { Active, not } \\
\text { recruiting }\end{array}$ & M7824 \\
\hline $\begin{array}{l}\text { Bintrafusp } \\
\text { alfa (M7824) }\end{array}$ & NCT04708470 & Advanced Cancer & $|/| \mid$ & $\begin{array}{l}\text { Not yet } \\
\text { recruiting }\end{array}$ & Entinostat, + NHS-IL12 + Bintrafusp alfa \\
\hline Bintrafusp & NCT04491955 & Advanced Small Bowel and & $\|$ & Recruiting & CEA/ MUC1 Vaccines + M7824 + N-803; \\
\hline
\end{tabular}


Table 1 Detailed information of the combination therapy of $\mathrm{ICl}$ and inhibitors of key molecules. (Continued)

\begin{tabular}{|c|c|c|c|c|c|c|}
\hline Drug & NCT No. & Tumor & Phase & Status & Therapy & Conclusion \\
\hline alfa (M7824) & & Colorectal Cancers & & & $\begin{array}{l}\text { CEA/ MUC1 Vaccines + M7824 + N-803 + } \\
\text { NHSIL12; }\end{array}$ & \\
\hline $\begin{array}{l}\text { Bintrafusp } \\
\text { alfa (M7824) }\end{array}$ & NCT03427411 & HPV Associated Malignancies & $\|$ & $\begin{array}{l}\text { Active, not } \\
\text { recruiting }\end{array}$ & M7824 & / \\
\hline $\begin{array}{l}\text { Bintrafusp } \\
\text { alfa (M7824) }\end{array}$ & NCT04287868 & $\begin{array}{l}\text { Advanced HPV Associated } \\
\text { Malignancies }\end{array}$ & $|/| \mid$ & Recruiting & PDS0101 + NHS IL12 + M7824 & / \\
\hline $\begin{array}{l}\text { Bintrafusp } \\
\text { alfa (M7824) }\end{array}$ & NCT03840915 & Stage IV NSCLC & $|/| \mid$ & $\begin{array}{l}\text { Active, not } \\
\text { recruiting }\end{array}$ & $\begin{array}{l}\text { Cisplatin or Carboplatin + Pemetrexed + } \\
\text { M7824; } \\
\text { Carboplatin + Paclitaxel or Nab-paclitaxel } \\
\text { + M7824; } \\
\text { Cisplatin or Carboplatin + Gemcitabine + } \\
\text { M7824; } \\
\text { Docetaxel + M7824 }\end{array}$ & / \\
\hline $\begin{array}{l}\text { Bintrafusp } \\
\text { alfa (M7824) }\end{array}$ & NCT04417660 & $\begin{array}{l}\text { Thymoma and Thymic } \\
\text { Carcinoma }\end{array}$ & $\|$ & Recruiting & M7824 & / \\
\hline $\begin{array}{l}\text { Bintrafusp } \\
\text { alfa (M7824) }\end{array}$ & NCT04247282 & $\begin{array}{l}\text { Resectable Head and Neck } \\
\text { Squamous Cell Carcinoma Not } \\
\text { Associated With Human } \\
\text { Papillomavirus Infection }\end{array}$ & $|/| \mid$ & Recruiting & $\begin{array}{l}\text { M7824; } \\
\text { M7824 + TriAd vaccine; } \\
\text { M7824 + TriAd vaccine + N-803 }\end{array}$ & / \\
\hline $\begin{array}{l}\text { Bintrafusp } \\
\text { alfa (M7824) }\end{array}$ & NCT04501094 & Urothelial Carcinoma & $\|$ & Recruiting & M7824 & / \\
\hline $\begin{array}{l}\text { Bintrafusp } \\
\text { alfa (M7824) }\end{array}$ & NCT04560686 & $\begin{array}{l}\text { Untreated Resectable Non-small } \\
\text { Cell Lung Cancer }\end{array}$ & ॥ & Recruiting & Bintrafusp alfa + surgical resection & / \\
\hline $\begin{array}{l}\text { Bintrafusp } \\
\text { alfa (M7824) }\end{array}$ & NCT03493945 & Advanced Prostate cancer & $|/| \mid$ & Recruiting & $\begin{array}{l}\text { M7824 + ALT-803; } \\
\text { M7824 + BN-Brachyury; } \\
\text { M7824 + BN-Brachyury + ALT-803; } \\
\text { M7824 + BN-Brachyury + ALT-803 + } \\
\text { Epacadostat }\end{array}$ & / \\
\hline $\begin{array}{l}\text { Bintrafusp } \\
\text { alfa (M7824) }\end{array}$ & NCT04349280 & $\begin{array}{l}\text { Metastatic or Locally Advanced } \\
\text { Urothelial Cancer }\end{array}$ & । & Recruiting & Bintrafusp alfa & / \\
\hline $\begin{array}{l}\text { Bintrafusp } \\
\text { alfa (M7824) }\end{array}$ & NCT03315871 & Recurrent Prostate Cancer & $\|$ & Recruiting & $\begin{array}{l}\text { PROSTVAC-V + PROSTVAC-F + M7824 + } \\
\text { CV301; }\end{array}$ & / \\
\hline $\begin{array}{l}\text { Bintrafusp } \\
\text { alfa (M7824) }\end{array}$ & NCT04727541 & Resectable Biliary Tract Cancer & $\|$ & $\begin{array}{l}\text { Not yet } \\
\text { recruiting }\end{array}$ & Neoadjuvant therapy with Bintrafusp alfa & / \\
\hline $\begin{array}{l}\text { Bintrafusp } \\
\text { alfa (M7824) }\end{array}$ & NCT04551950 & Cervical Cancer & । & Recruiting & $\begin{array}{l}\text { M7824+cisplatin; } \\
\text { M7824 + cisplatin or carboplatin + } \\
\text { paclitaxel; } \\
\text { M7824+cisplatin+ radiotherapy }\end{array}$ & / \\
\hline $\begin{array}{l}\text { Bintrafusp } \\
\text { alfa (M7824) }\end{array}$ & NCT03451773 & $\begin{array}{l}\text { Advanced Adenocarcinoma of } \\
\text { the Pancreas }\end{array}$ & $|/| \mid$ & Completed & Gemcitabine + M7824 & / \\
\hline $\begin{array}{l}\text { Bintrafusp } \\
\text { alfa (M7824) }\end{array}$ & NCT04595149 & $\begin{array}{l}\text { Esophageal Squamous Cell } \\
\text { Carcinoma }\end{array}$ & $\|$ & Recruiting & Bintrafusp alfa + Paclitaxel + Carboplatin & / \\
\hline $\begin{array}{l}\text { Bintrafusp } \\
\text { alfa (M7824) }\end{array}$ & NCT04220775 & $\begin{array}{l}\text { Recurrent or Second Primary } \\
\text { Head and Neck Squamous Cell } \\
\text { Cancer }\end{array}$ & $|/| \mid$ & Recruiting & Bintrafusp alfa + SBRT & / \\
\hline $\begin{array}{l}\text { Bintrafusp } \\
\text { alfa (M7824) }\end{array}$ & NCT04756505 & $\begin{array}{l}\text { Hormone Receptor Positive, } \\
\text { HER2 Negative Metastatic Breast } \\
\text { Cancer }\end{array}$ & । & $\begin{array}{l}\text { Not yet } \\
\text { recruiting }\end{array}$ & $\begin{array}{l}\text { Bintrafusp alfa + NHS-IL12 + radiation } \\
\text { therapy }\end{array}$ & / \\
\hline $\begin{array}{l}\text { Bintrafusp } \\
\text { alfa (M7824) }\end{array}$ & NCT04396535 & $\begin{array}{l}\text { Advanced Non-small Cell Lung } \\
\text { Cancer }\end{array}$ & $\|$ & Recruiting & Docetaxel + B zintrafusp alfa & / \\
\hline $\begin{array}{l}\text { Bintrafusp } \\
\text { alfa (M7824) }\end{array}$ & NCT04789668 & Mutilple Stage IV cancers & $|/| \mid$ & Recruiting & bintrafusp alfa + Pimasertib & / \\
\hline $\begin{array}{l}\text { Bintrafusp } \\
\text { alfa (M7824) }\end{array}$ & NCT04648826 & $\begin{array}{l}\text { Unresectable Pulmonary } \\
\text { Metastases From Sarcomas, } \\
\text { Germ Cell Tumors, or Epithelial } \\
\text { Malignancies }\end{array}$ & $|/| \mid$ & $\begin{array}{l}\text { Not yet } \\
\text { recruiting }\end{array}$ & Azacytidine+ Bintrafusp alfa & / \\
\hline Bintrafusp & NCT03707587 & Recurrent Respiratory & $\|$ & Active, not & M7824 & CR: $0 / 7$ and $0 /$ \\
\hline
\end{tabular}


Table 1 Detailed information of the combination therapy of $\mathrm{ICl}$ and inhibitors of key molecules. (Continued)

\begin{tabular}{|c|c|c|c|c|c|c|}
\hline Drug & NCT No. & Tumor & Phase & Status & Therapy & Conclusion \\
\hline alfa (M7824) & & Papillomatosis & & recruiting & & $\begin{array}{l}2 \text { in } \mathrm{ICI} \text { naïve } \\
\text { patients and } \\
\mathrm{ICI} \text { refractory; } \\
\mathrm{PR}: 1 / 7 \text { and } 0 / 2\end{array}$ \\
\hline $\begin{array}{l}\text { Bintrafusp } \\
\text { alfa (M7824) }\end{array}$ & NCT04303117 & Advanced Kaposi Sarcoma & $|/| \mid$ & Recruiting & NHSIL12 + M7824 & / \\
\hline $\begin{array}{l}\text { Bintrafusp } \\
\text { alfa (M7824) }\end{array}$ & NCT04428047 & $\begin{array}{l}\text { Operable and Untreated Head } \\
\text { and Neck Squamous Cell } \\
\text { Carcinoma }\end{array}$ & $\|$ & Recruiting & M7824 & / \\
\hline $\begin{array}{l}\text { Bintrafusp } \\
\text { alfa (M7824) }\end{array}$ & NCT04708067 & $\begin{array}{l}\text { Advanced Intrahepatic } \\
\text { Cholangiocarcinoma }\end{array}$ & I & $\begin{array}{l}\text { Not yet } \\
\text { recruiting }\end{array}$ & $\begin{array}{l}\text { Hypofractionated radiation + Bintrafusp } \\
\text { alfa }\end{array}$ & / \\
\hline \multicolumn{7}{|l|}{ Anti-TGF $\beta R 1$} \\
\hline Galunisertib & NCT02734160 & Metastatic Pancreatic Cancer & I & Completed & Galunisertib + Durvalumab & / \\
\hline Galunisertib & NCT02423343 & $\begin{array}{l}\text { Recurrent or Refractory NSCLC, } \\
\text { or Hepatocellular Carcinoma }\end{array}$ & $|/| \mid$ & Completed & Galunisertib + Nivolumab & / \\
\hline $\begin{array}{l}\text { Vactosertib } \\
\text { (TEW-7197) }\end{array}$ & NCT03724851 & $\begin{array}{l}\text { Metastatic Colorectal or Gastric } \\
\text { Cancer }\end{array}$ & $|/| \mid$ & Recruiting & TEW-7197 + Pembrolizumab & / \\
\hline $\begin{array}{l}\text { Vactosertib } \\
\text { (TEW-7197) }\end{array}$ & NCT03732274 & Advanced NSCLC & $|/| \mid$ & $\begin{array}{l}\text { Active, not } \\
\text { recruiting }\end{array}$ & TEW-7197 + Durvalumab & / \\
\hline $\begin{array}{l}\text { Vactosertib } \\
\text { (TEW-7197) }\end{array}$ & NCT04064190 & Urothelial Carcinoma & $\|$ & $\begin{array}{l}\text { Not yet } \\
\text { recruiting }\end{array}$ & Vactosertib + Durvalumab & / \\
\hline $\begin{array}{l}\text { Vactosertib } \\
\text { (TEW-7197) }\end{array}$ & NCT04515979 & PD-L1 Positive NSCLC & $\|$ & Recruiting & Vactosertib + Pembrolizumab & / \\
\hline LY3200882 & NCT04158700 & Advanced Cancer & $|/| \mid$ & Withdrawn & LY3200882 + Pembrolizumab & / \\
\hline \multicolumn{7}{|l|}{ Anti-IL-6R } \\
\hline Tocilizumab & NCT04691817 & Non-Small Cell Lung Cancer & $|/| \mid$ & $\begin{array}{l}\text { Not yet } \\
\text { recruiting }\end{array}$ & Atezolizumab + Tocilizumab & / \\
\hline Tocilizumab & NCT04258150 & Advanced Pancreatic Cancer & $\|$ & $\begin{array}{l}\text { Active, not } \\
\text { recruiting }\end{array}$ & $\begin{array}{l}\text { Nivolumab + Ipilimumab + Tocilizumab + } \\
\text { Radiation }\end{array}$ & / \\
\hline Tocilizumab & NCT04524871 & Advanced Liver Cancers & $|/| \mid$ & Recruiting & $\begin{array}{l}\text { Atezolizumab + Bevacizumab + } \\
\text { Tocilizumab }\end{array}$ & / \\
\hline Tocilizumab & NCT03588936 & $\begin{array}{l}\text { Relapsed Hematological } \\
\text { Malignancy }\end{array}$ & I & Terminated & Nivolumab + Tocilizumab & / \\
\hline Tocilizumab & NCT03821246 & Prostate Cancer & $\|$ & Recruiting & Atezolizumab + Tocilizumab & / \\
\hline Tocilizumab & NCT03708224 & $\begin{array}{l}\text { Squamous Cell Carcinoma of the } \\
\text { Head and Neck }\end{array}$ & $\|$ & Recruiting & Atezolizumab + Tocilizumab & / \\
\hline Tocilizumab & NCT03424005 & $\begin{array}{l}\text { Metastatic or Inoperable Locally } \\
\text { Advanced Triple-Negative Breast } \\
\text { Cancer }\end{array}$ & $|/| \mid$ & Recruiting & $\begin{array}{l}\text { Atezolizumab + Nab-Paclitaxel + } \\
\text { Tocilizumab }\end{array}$ & / \\
\hline Tocilizumab & NCT04729959 & Recurrent Glioblastoma & $\|$ & $\begin{array}{l}\text { Not yet } \\
\text { recruiting }\end{array}$ & $\begin{array}{l}\text { Atezolizumab + Tocilizumab + Radiation; } \\
\text { Atezolizumab + Tocilizumab + Radiation + } \\
\text { Surgery }\end{array}$ & / \\
\hline Tocilizumab & NCT03866239 & $\begin{array}{l}\text { Metastatic Colorectal } \\
\text { Adenocarcinoma }\end{array}$ & । & Recruiting & $\begin{array}{l}\text { Obinutuzumab + Cibisatamab + } \\
\text { Atezolizumab }+ \text { Tocilizumab }\end{array}$ & / \\
\hline Tocilizumab & NCT03869190 & Urothelial Carcinoma & $|/| \mid$ & Recruiting & Atezolizumab + Tocilizumab & / \\
\hline Tocilizumab & NCT03337698 & $\begin{array}{l}\text { Metastatic Non-Small Cell Lung } \\
\text { Cancer }\end{array}$ & $|/| \mid$ & Recruiting & Atezolizumab + RO6958688 + Tocilizumab & / \\
\hline Tocilizumab & NCT03999749 & $\begin{array}{l}\text { Unresectable Stage III or Stage } \\
\text { IV Melanoma }\end{array}$ & $\|$ & Recruiting & Ipilimumab + Nivolumab + Tocilizumab & / \\
\hline Tocilizumab & NCT03533283 & Non-Hodgkins Lymphoma & I & Recruiting & $\begin{array}{l}\text { Glofitamab + Atezolizumab + } \\
\text { Obinutuzumab + Tocilizumab }\end{array}$ & / \\
\hline \multicolumn{7}{|l|}{ Anti-Arginase } \\
\hline INCB001158 & NCT03910530 & Advanced Solid Tumors & । & Active, not & Retifanlimab + INCB001158 & / \\
\hline
\end{tabular}


Table 1 Detailed information of the combination therapy of $\mathrm{ICl}$ and inhibitors of key molecules. (Continued)

\begin{tabular}{|c|c|c|c|c|c|c|}
\hline Drug & NCT No. & Tumor & Phase & Status & Therapy & Conclusion \\
\hline & & & & recruiting & & \\
\hline INCB001158 & NCT03361228 & Advanced Solid Tumors & $|/| \mid$ & Terminated & $\begin{array}{l}\text { INCB001158 + Epacadostat + } \\
\text { Pembrolizumab }\end{array}$ & / \\
\hline INCB001158 & NCT02903914 & $\begin{array}{l}\text { Advanced/Metastatic Solid } \\
\text { Tumors }\end{array}$ & $|/| \mid$ & $\begin{array}{l}\text { Active, not } \\
\text { recruiting }\end{array}$ & INCB001158 + Pembrolizumab & / \\
\hline \multicolumn{7}{|l|}{ Anti-CD39 } \\
\hline IPH5201 & NCT04261075 & Advanced Solid Tumors & । & Recruiting & $\begin{array}{l}\text { IPH5201 + Durvalumab; } \\
\text { IPH5201 + Durvalumab + Oleclumab }\end{array}$ & / \\
\hline TTX-030 & NCT04306900 & Advanced Cancers & । & Recruiting & $\begin{array}{l}\text { TTX-030 + Budigalimab; } \\
\text { TX-030 + Budigalimab + Docetaxel; } \\
\text { TTX-030 + Budigalimab + mFOLFOX6 }\end{array}$ & / \\
\hline TTX-030 & NCT03884556 & Advanced Cancers & । & Recruiting & TTX-030 + Pembrolizumab & / \\
\hline \multicolumn{7}{|c|}{ Anti-CD39 (mAb) } \\
\hline SRF617 & NCT04336098 & Advanced Solid Tumors & । & Recruiting & SRF617 + Pembrolizumab & / \\
\hline \multicolumn{7}{|c|}{ Anti-CD73 (mAb) } \\
\hline CPI-006 & NCT03454451 & Advanced Cancers & । & Recruiting & CPI-006 + Pembrolizumab & / \\
\hline AB680 & NCT04104672 & Gastrointestinal Malignancies & । & Recruiting & $\begin{array}{l}\text { AB680 + Zimberelimab + Nab-paclitaxel + } \\
\text { Gemcitabine }\end{array}$ & / \\
\hline AB680 & NCT04381832 & $\begin{array}{l}\text { Metastatic Castrate Resistant } \\
\text { Prostate Cancer }\end{array}$ & $|/| \mid$ & Recruiting & Etrumadenant + Zimberelimab & / \\
\hline AB680 & NCT04660812 & Metastatic Colorectal Cancer & $|/| \mid$ & Recruiting & Etrumadent+ Zimberelimab + AB680 & / \\
\hline TJ004309 & NCT04322006 & Advanced Solid Tumor & $|/| \mid$ & Recruiting & PD-1 monoclonal antibody + TJ004309 & / \\
\hline TJ004309 & NCT03835949 & Advanced or Metastatic Cancer & । & Recruiting & TJ004309 + Atezolizumab & / \\
\hline BMS-986179 & NCT02754141 & Solid Tumor & $|/| \mid$ & $\begin{array}{l}\text { Active, not } \\
\text { recruiting }\end{array}$ & BMS-986179 + Nivolumab & / \\
\hline $\begin{array}{l}\text { Oleclumab } \\
\text { (MEDI9447) }\end{array}$ & NCT02503774 & Select Advanced Solid Tumors & । & Completed & Oleclumab + Durvalumab & / \\
\hline $\begin{array}{l}\text { Oleclumab } \\
\text { (MEDI9447) }\end{array}$ & NCT03611556 & $\begin{array}{l}\text { Metastatic Pancreatic } \\
\text { Adenocarcinoma }\end{array}$ & $|/| \mid$ & Recruiting & Oleclumab + Durvalumab + mFOLFOX & / \\
\hline $\begin{array}{l}\text { Oleclumab } \\
\text { (MEDI9447) }\end{array}$ & NCT03773666 & Muscle-invasive Bladder Cancer & । & Recruiting & Durvalumab + Oleclumab & / \\
\hline $\begin{array}{l}\text { Oleclumab } \\
\text { (MEDI9447) }\end{array}$ & NCT04262375 & $\begin{array}{l}\text { Non Small Cell Lung Cancer; } \\
\text { Renal Cell Carcinoma }\end{array}$ & $\|$ & Withdrawn & Durvalumab + Oleclumab & / \\
\hline $\begin{array}{l}\text { Oleclumab } \\
\text { (MEDI9447) }\end{array}$ & NCT04262388 & $\begin{array}{l}\text { Pancreatic Ductal } \\
\text { Adenocarcinoma; Non-small Cell } \\
\text { Lung Cancer; Squamous Cell } \\
\text { Carcinoma of Head and Neck }\end{array}$ & $\|$ & Withdrawn & Durvalumab + Oleclumab & / \\
\hline $\begin{array}{l}\text { Oleclumab } \\
\text { (MEDI9447) }\end{array}$ & NCT03616886 & Triple Negative Breast Cancer & $|/| \mid$ & Recruiting & $\begin{array}{l}\text { Paclitaxel + Carboplatin + Durvalumab + } \\
\text { Oleclumab }\end{array}$ & / \\
\hline $\begin{array}{l}\text { Oleclumab } \\
\text { (MEDI9447) }\end{array}$ & NCT03267589 & Relapsed Ovarian Cancer & $\|$ & Recruiting & Durvalumab + Oleclumab & / \\
\hline $\begin{array}{l}\text { Oleclumab } \\
\text { (MEDI9447) }\end{array}$ & NCT04089553 & Prostate Cancer & $\|$ & Recruiting & AZD4635 + Durvalumab + Oleclumab & / \\
\hline $\begin{array}{l}\text { Oleclumab } \\
\text { (MEDI9447) }\end{array}$ & NCT04668300 & $\begin{array}{l}\text { Recurrent, Refractory, or } \\
\text { Metastatic Sarcoma }\end{array}$ & $\|$ & Recruiting & Durvalumab + Oleclumab & / \\
\hline $\begin{array}{l}\text { Oleclumab } \\
\text { (MEDI9447) }\end{array}$ & NCT03875573 & Luminal B Breast Cancer & $\|$ & $\begin{array}{l}\text { Active, not } \\
\text { recruiting }\end{array}$ & $\begin{array}{l}\text { Chemotherapy \& pre-op radiotherapy }+ \\
\text { Durvalumab }+ \text { Oleclumab }\end{array}$ & / \\
\hline $\begin{array}{l}\text { Oleclumab } \\
\text { (MEDI9447) }\end{array}$ & NCT03833440 & Non-small Cell Lung Cancer & $\|$ & Recruiting & Durvalumab + MEDI9447 & / \\
\hline $\begin{array}{l}\text { Oleclumab } \\
\text { (MEDI9447) }\end{array}$ & NCT03819465 & Untreated NSCLC & । & $\begin{array}{l}\text { Active, not } \\
\text { recruiting }\end{array}$ & $\begin{array}{l}\text { Durvalumab + Oleclumab; Durvalumab + } \\
\text { investigator's choice of chemotherapy }+ \\
\text { Oleclumab }\end{array}$ & / \\
\hline
\end{tabular}


Table 1 Detailed information of the combination therapy of $\mathrm{ICl}$ and inhibitors of key molecules. (Continued)

\begin{tabular}{|c|c|c|c|c|c|c|}
\hline Drug & NCT No. & Tumor & Phase & Status & Therapy & Conclusion \\
\hline $\begin{array}{l}\text { Oleclumab } \\
\text { (MEDI9447) }\end{array}$ & NCT04068610 & $\begin{array}{l}\text { Metastatic Microsatellite-stable } \\
\text { Colorectal Cancer }\end{array}$ & $|/| \mid$ & $\begin{array}{l}\text { Active, not } \\
\text { recruiting }\end{array}$ & $\begin{array}{l}\text { FOLFOX + Bevacuzimab + Durvalumab + } \\
\text { Oleclumab }\end{array}$ & I \\
\hline $\begin{array}{l}\text { Oleclumab } \\
\text { (MEDI9447) }\end{array}$ & NCT03822351 & NSCLC & $\|$ & $\begin{array}{l}\text { Active, not } \\
\text { recruiting }\end{array}$ & Durvalumab + Oleclumab & / \\
\hline $\begin{array}{l}\text { Oleclumab } \\
\text { (MEDI9447) }\end{array}$ & NCT03742102 & $\begin{array}{l}\text { Metastatic Triple Negative Breast } \\
\text { Cancer }\end{array}$ & $|/| \mid$ & Recruiting & Durvalumab + Paclitaxel + Oleclumab & / \\
\hline $\begin{array}{l}\text { Oleclumab } \\
\text { (MEDI9447) }\end{array}$ & NCT02740985 & Advanced Solid Malignancies & I & $\begin{array}{l}\text { Active, not } \\
\text { recruiting }\end{array}$ & AZD4635 + Durvalumab + Oleclumab & / \\
\hline $\begin{array}{l}\text { Oleclumab } \\
\text { (MEDI9447) }\end{array}$ & NCT04145193 & $\begin{array}{l}\text { Microsatellite-stable Colorectal } \\
\text { Cancer }\end{array}$ & $\|$ & Withdrawn & $\begin{array}{l}\text { mFOLFOX6 + Durvalumab + Oleclumab + } \\
\text { Monalizumab }\end{array}$ & / \\
\hline $\begin{array}{l}\text { Oleclumab } \\
\text { (MEDI9447) }\end{array}$ & NCT03334617 & $\begin{array}{l}\text { NSCLC Who Progressed on an } \\
\text { Anti-PD-1/PD-L1 Containing } \\
\text { Therapy }\end{array}$ & $\|$ & Recruiting & Durvalumab + Oleclumab & / \\
\hline $\begin{array}{l}\text { NZV930 } \\
\text { (SRF373) }\end{array}$ & NCT03549000 & Advanced Malignancies & I & Recruiting & $\begin{array}{l}\text { NZV930 + PDR001; NZV930 + NIR178 + } \\
\text { PDR001 }\end{array}$ & / \\
\hline LY-3475070 & NCT04148937 & Advanced Cancer & I & Recruiting & LY3475070 + Pembrolizumab & / \\
\hline \multicolumn{7}{|l|}{ Anti-COX-2 } \\
\hline Celecoxib & NCT03728179 & $\begin{array}{l}\text { Advanced TIL-negative Solid } \\
\text { Tumors }\end{array}$ & । & Recruiting & $\begin{array}{l}\text { RT + Cyclophosphamide + Nivolumab + } \\
\text { Celecoxib/;RT + Nivolumab + Ipilimumab } \\
\text { or Cyclophosphamide + Celecoxib; RT + } \\
\text { Ipilimumab + Nivolumab + Celecoxib }\end{array}$ & / \\
\hline Celecoxib & NCT04348747 & $\begin{array}{l}\text { Brain Metastasis From Triple } \\
\text { Negative Breast Cancer or } \\
\text { HER2+ Breast Cancer }\end{array}$ & $\|$ & $\begin{array}{l}\text { Not yet } \\
\text { recruiting }\end{array}$ & $\begin{array}{l}\text { Anti-HER2/3 dendritic cell vaccine }+ \\
\text { Celecoxib }+ \text { Pembrolizumab }+ \\
\text { recombinant interferon alfa- } 2 \mathrm{~b}+ \\
\text { Rintatolimod }\end{array}$ & / \\
\hline Celecoxib & NCT03599453 & $\begin{array}{l}\text { Metastatic Triple-Negative Breast } \\
\text { Cancer }\end{array}$ & Early I & $\begin{array}{l}\text { Active, not } \\
\text { recruiting }\end{array}$ & $\begin{array}{l}\text { Celecoxib + Recombinant Interferon Alfa- } \\
2 b+\text { Rintatolimod + Pembrolizumab }\end{array}$ & / \\
\hline Celecoxib & NCT03026140 & Early Stage Colon Cancer & $\|$ & Recruiting & Nivolumab + Ipilimumab + Celecoxib & / \\
\hline Celecoxib & NCT03638297 & $\begin{array}{l}\text { MSI-H/dMMR or High TMB } \\
\text { Colorectal Cancer }\end{array}$ & $\|$ & Recruiting & PD-1 antibody + Cox inhibitor & / \\
\hline
\end{tabular}

support the association of TLR targeting antagonists or inhibitors of MDSC.

\section{S100A8/9}

S100 calcium-binding protein A9 (S100A9) is a member of the S100 family of proteins and is also known as calgranulin B. The proteins S100A8 and S100A9 form a heterodimer, calprotectin, to function. S100A9 is prevalently reported to have significant roles in multiple processes of MDSC involved activity in tumor context, including MDSC recruitment [44], MDSC induced tumorigenesis [82] and tumor progression [83]. S100A9 can alter the direction of myeloid cell toward MDSC, not dendritic cell (DC) and macrophage. Enhanced secretion of S100A9 by MDSC therefore forms a selfamplified feedback mechanism to maintain the differentiation of MDSC [162, 163]. Another study reported that S100A9, produced by MDSC, can promote the angiogenesis and metastasis of multiple myeloma [164]. Evidence has shown that $\mathrm{S} 100 \mathrm{~A} 8 / 9$ is a significant participant in almost the entire course of MDSC activity in the tumor microenvironment. S100A8/9, therefore, might be an eligible target for MDSC inhibiting. And inhibitor of S100A8/9 might be a suitable candidate for a combined therapy with ICI agents in tumor treatment. The application of existing agents that target S100A8/9, such as tasquinimod, have not been designed in combination with immunotherapy agents in clinical trials, which may be worth considering in the future.

\section{PGE2}

Prostaglandin E2 (PGE2), or dinoprostone, is a naturally occurring prostaglandin with oxytocic properties that is prevalently used as medication. PGE2 is also a key factor that has critical roles in MDSC chemoattraction [35], pre-metastatic niche formation [105, 107], and MDSC related tumorigenesis [77]. Otherwise, PGE2 has been demonstrated to induce CXCL1 and CXCL2 expression in the colonic mucosa and tumors, which leads to the chemoattraction of MDSC and promotes the colitisassociated tumorigenesis [22]. PGE2 is revealed to prevent the differentiation of $\mathrm{DC}$, while accelerating the differentiation toward MDSC [165]. A similar observation was reported in another study on HCC [166]. PGE2 is 
capable of enhancing the production of TGF- $\beta$, another key molecule in the MDSC-involved microenvironment, through the augmentation of the p38/MAPK pathway [70]. PGE2 is synthesized from arachidonic acid by cyclooxygenase (COX), and inhibiting COX-2 activity is an effective way of PGE2 inhibition [167]. Celecoxib, a selective inhibitor of COX-2 that may have the ability of MDSC inhibition by downregulating PGE2, has also been suggested for a combination therapy with ICI, which is currently being applied in several active clinical trials.

\section{CD39/CD73}

CD39 and CD73 are ectonucleotidases that serve to convert ATP/ADP to adenosine, which play a vital role in immunosuppression. Significant expression of CD39/CD73 is detected on the surface of MDSC [63], which is also proposed to promote angiogenic factors production in the colon cancer microenvironment [87]. Upregulation of CD73 in MDSC is identified to be conducted by TGF- $\beta$, a crucial molecule in the MDSC-induced immunosuppressive microenvironment, activating mTOR/HIF- $1 \alpha$ signaling [63]. The evidence mentioned above suggests that CD39/CD73 activity is an important mechanism of MDSC-induced immunosuppression, therefore, inhibiting CD39/CD73 might be a reasonable strategy for MDSC controlling or in a combination with immunotherapy. Anti-CD39 and anti-CD73 antibody administrations can significantly inhibit the immunosuppressive effect of MDSC, as evidenced by in vitro and in vivo experiments $[168,169]$. In addition, multiple clinical trials have been registered to explore the strategy of CD39/CD73 targeting and that combined with ICIs. However, vast majority of these are in an earlier stage (phase I to II).

\section{TGF- $\beta$}

As reviewed above, TGF- $\beta$ has been demonstrated as a key participant in MDSC recruitment and immunosuppressive function of MDSC. Intriguingly, TGF- $\beta$ in cancer also has a two-sided effect on MDSC differentiation. On one hand, TGF- $\beta$ maintains the differentiation and expansion of MDSCs (mainly M-MDSC not PMN-MDSC [170]) by downregulating IRF8 through upregulating the expression of inhibitor of DNA-binding 1 (ID1) [171]. On the other hand, researchers expound that TGF- $\beta$ induces the generation of a unique MDSC population (TGF- $\beta$ MDSC) through a SMAD-2-dependent signaling mechanism, which leads to the augmented expression of surface markers factor associated suicide ligand (FAS-L), CD86, and MHC II. TGF- $\beta$-MDSC has been also reported to inhibit $\mathrm{T}$ cell proliferation, as well as mediate cancer cell apoptosis [172]. Several drugs that target TGF- $\beta$ have been designed for combination with ICIs in clinical trials (mainly in early-stage), including a) TGF- $\beta$ inhibitors:
ABBV-151 and pirfenidone, b) TGF- $\beta$ antibodies: NIS793 and SAR439459, c) TGF- $\beta R 1$ inhibitors: galunisertib and vactosertib (TEW-7197), and d) bintrafusp alfa (M7824), a bifunctional fusion protein of the PD-L1 antibody with two conjugated TGF- $\beta$-neutralizing trap components that targets PD-L1 and TGF- $\beta$ pathways.

\section{IL-6}

Interleukin 6 (IL-6) is an important interleukin that acts in a dual directional regulation manner, pro-inflammatory and anti-inflammatory [173], which has been confirmed to play crucial roles in various inflammation related conditions including cancers. As described above, IL-6 exerts an augmented impact on MDSC induced activity, including IDO production and cripple of Th1 cell differentiation [59], enhanced cancer cell stem cell like properties [85], and tumor metastasis [97, 106]. Accumulating evidence has emerged suggesting IL- 6 as a vital factor for MDSC activity in the tumor microenvironment. IL-6-induced upregulation of CCR5 and CXCR2 expression in MDSC has been proposed as a significant mechanism of MDSC attraction [174]. IL-6/STAT3 signaling has been identified necessary for the survival of intestinal epithelial cells, which also plays an important role in colitis-associated tumorigenesis [80]. IL-6 has also been demonstrated to induce MDSC expansion in the process of colitis-associated tumorigenesis and enhance the immunosuppressive function [22]. IL-6 levels have been revealed significantly associated with MDSC levels in the colonic mucosa and tumors, as well as in the circulatory system [80]. Besides, evidence has hinted that IL- 6 can induce the differentiation of myeloid cells into S100A8/9-expressing MDSC by STAT3 signaling in the colorectal cancer, and prevents the differentiation of MDSC into DCs and macrophages $[162,163]$. Therefore, targeting IL-6 is a reasonable strategy for MDSC management, and attempts in combination application with ICIs in tumor treatment are warranted. Several clinical trials have been registered to explore on ICIs plus tocilizumab, an IL-6R mAb drug, in tumor treating. However, no results have yet been posted that are noteworthy.

\section{Other regimens modulating MDSC}

Except for targeting key molecules in the MDSCinduced tumor microenvironment, several drugs have been proved to have the potential to restrain MDSC, and improve the clinical benefit of immunotherapies. Multi-target tyrosine kinase inhibitors (TKIs), including cabozantinib, sunitinib, and sorafenib, were shown to reduce the number and activity of MDSCs in preclinical and clinical studies [175]. Based on these, plenty of clinical trials have been designed to investigate the efficacy of regimens combining TKI and immunotherapy. Cabozantinib is the most popular TKI candidate with 41 
clinical trials (including seven phase III trials and 23 phase II trials) of combination therapies, covering most types of solid cancers. Recently, a phase III randomized controlled trial (RCT) of nivolumab and cabozantinib in advanced renal-cell carcinoma (CheckMate 9ER) has reported a superior efficacy of the combination strategy compared with standard treatment in renal-cell carcinoma, sunitinib [176]. Both progression free survival (PFS) and OS were improved significantly in patients receiving nivolumab and cabozantinib. This is compelling evidence that modulating MDSC may be a vigorous strategy to boost the potential of immunotherapy. In addition to cabozantinib, sunitinib and sorafenib also have several clinical trials ongoing in combination with ICIs, mainly focused on renal and hepatocellular carcinoma (Fig 6).

PI3K inhibitors, such as eganelisib, and duvelisib, were also suggested to restrain immunosuppression through inhibiting of MDSC [177]. Relative clinical trials are now ongoing in solid cancers, mainly focusing on combinations with ipilimumab, nivolumab, and pembrolizumab. Another important drug type of this strategy is BTK inhibitors with several evidences demonstrating their MDSC-modulating potential [178]. Ibrutinib and acalabrutinib, as representatives of BTK inhibitors, have 30 clinical phase I or II RCTs on hematologic and solid malignancies registered in ClinicalTrials.gov. These trials are principally investigating combinations of BTK inhibitors with PD-1/ PD-L1 inhibitors. Notably, four trials are focusing on BTK inhibitors and CAR-T therapy. HDAC inhibitors were also proved to restrain MDSC [179]. Therefore, entinostat and azacytidine are popular candidates of combination therapy, with 38 clinical trials mainly focusing on hematologic malignancies.

Targeting STAT3 is also a common choice to suppress MDSC through mechanisms of blocking differentiation of MDSC and inducing apoptosis [180]. Danvatirsen and BBI608 now have six trials on solid malignancies in combination with multiple ICIs as partners in regimen. Besides, blocking recruitment signals of MDSC by CCR2/5 inhibition is also an alternative way [159, 181, 182]. Nevertheless, clinical attempts of combining CCR2/5 inhibitors and ICIs are limited. Vitamins, especially all-trans retinoic acid (ATRA), were unexpectedly demonstrated to have MDSC-restrain property [183189]. A few exploratory RCTs have been designed employing ATRA and ICIs in melanoma and MDS. Several other drugs which also regulate MDSC include PDE5 inhibitors, arginase inhibitor, and metformin [190-195]. Detailed information is shown in Fig 6.

\section{Conclusion and future perspective}

As emphasized in this review, MDSC has been identified to be one of the major contributors of immunosuppressive populations in tumor microenvironment, which proposes that the activity of MDSC should be advised in immunotherapy, including ICI administration and CAR-T. Studies from the pan-cancer perspective have identified that the frequency of circulating MDSC and its subsets are well-performed predicting factors of prognosis in multiple tumors. As noted above, MDSC may be a potential predicting factor of the clinical response of immunotherapies in tumors. Plenty of evidence from clinical studies have found that higher frequency of MDSC is significantly associated with poor response of ipilimumab in melanoma and other tumors; more adequate evidence is present for melanoma due to the fast advance of immunotherapy-related clinical trials in melanoma. Therefore, focusing on depleting MDSC in the tumor microenvironment in immunotherapy scenario may be one of the major directions of therapeutics.

Applying suitable MDSC inhibitors might be a potential strategy in immunotherapy. From the perspective of the molecular mechanism, there are generally three ways of limiting the activity of MDSC. a) Direct lethal attack on MDSC applying agents including TKIs, IL-6R inhibitors, S100A9 inhibitors, and metformin [192, 196-199]. Several clinical studies have mentioned about the depletion of MDSC after ICI administration, which may prompt that ICI itself may have an MDSC-inhibiting effect [200, 201]. b) Targeting the recruitment and maintenance of MDSC in tumor microenvironment; pre-clinical evidence has prompt that an antagonist of MDSC chemoattractant can deplete MDSC effectively [202]. c) Targeting immunosuppressive effectors; for instance, targeting IDO, one major effector of immunosuppression of MDSC, was believed to have promising clinical benefits in treating tumors combined with ICI. However, a phase III clinical trial (ECHO301/KEYNOTE-252) revealed that pembrolizumab plus epacadostat treatment in melanoma failed to improve PFS or OS compared with placebo [203], which led to the withdrawal of numerous ongoing clinical trials of IDO antagonist plus ICI. Other four phase III studies of pembrolizumab plus epacadostat in urothelial cancer, RCC, and HNSCC showed a seemingly higher objective response rate compared with the control group (NCT03361865; NCT03374488; NCT03260894; NCT03358472), which hints that difference in cancer type might lead to different effects. Otherwise, there is also a difference between clinical trials in study design and protocol. An optimized protocol also helps to better evaluation of the drug response; however, more studies are needed especially in melanoma. Still, a phase II study of Sipuleucel-T (tumor vaccine) plus indoximod (NCT01560923) in prostate cancer showed better PFS compared with Sipuleucel-T plus placebo, indicating that the same dosage form of IDO inhibitor may lead to different clinical outcomes in specific 


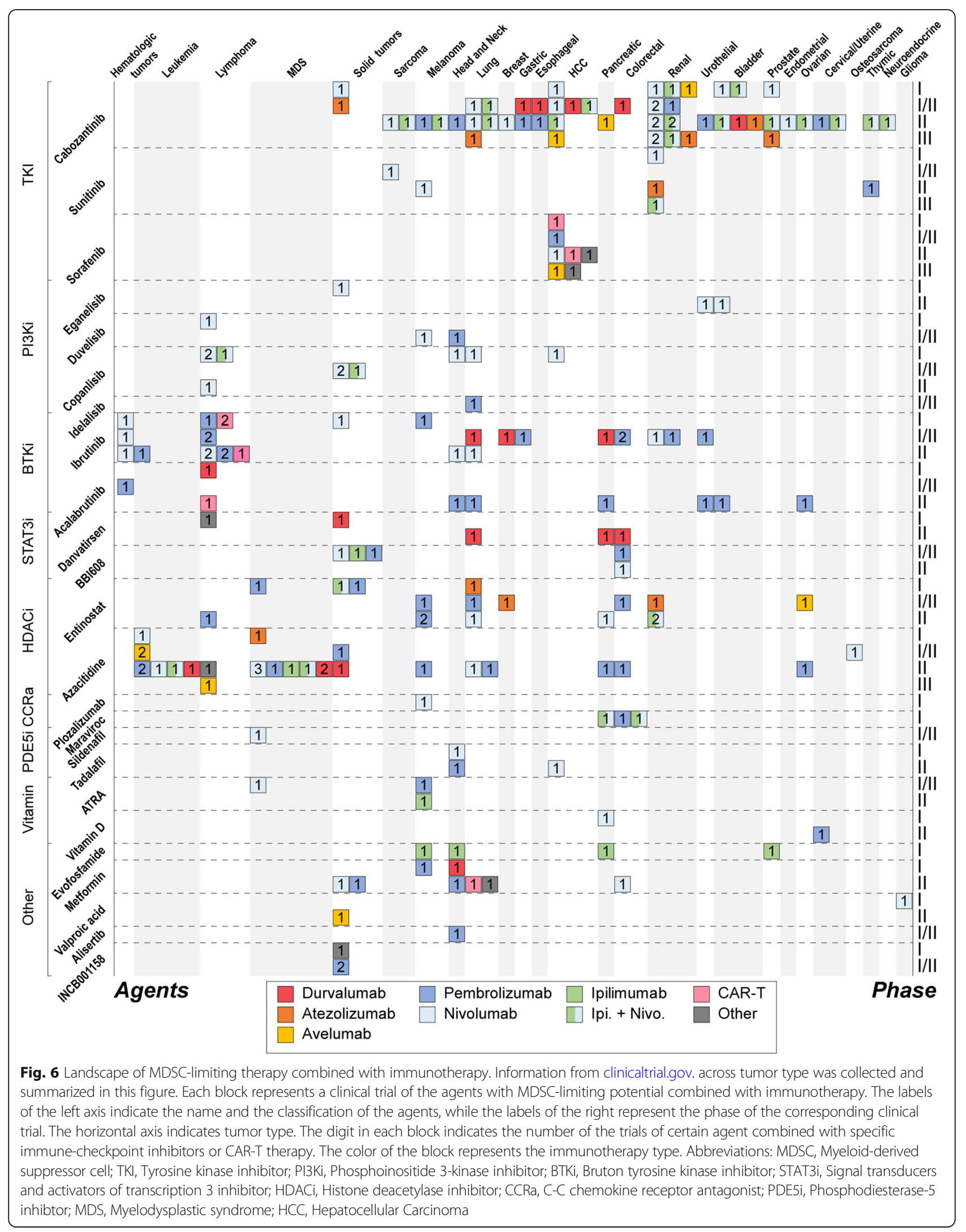


tumors. As for now, many attempt for the elimination of MDSC to improve immune response are undergoing [204], yet no consensus on the clinical benefit of inhibiting the immunosuppressive effectors of MDSC has been made; more optimized studies are still in need.

Generally, we proposed several core molecules that play vital roles in different biological processes related to MDSC activity, which may be potential targets of MDSC-inhibiting strategies that are suitable for combined application with immunotherapies in the upcoming clinical trials. Besides, several pre-existing drugs, which are found to have the potential to limit MDSC are also candidates for a combination strategy.

Overall, with the advances in cancer research, the scientific community has reached a common sense that cancers cannot be conquered by mono-therapy. The combination of surgery, chemotherapy, radiation therapy, and targeted therapy is becoming the leading edge in cancer treatment, along with the construction of a multi-dimensional therapy by combining the targets from the perspective of tumor immunity, tumor metabolism, and tumor epigenetics. In this systematic scenario of treatment, immunotherapy plays a decisive role that regulates the immune-microenvironment, and enhances the direct lethal impact of anti-tumor effectors, such as CTL. As highlighted in this review, MDSC exerts a great impact on both the regulation of the immunemicroenvironment and the response of immunotherapy. We therefore recommend that an MDSC-inhibiting strategy should be addressed or taken into consideration in all immunotherapy of cancers, including ICI treatment, CAR-T therapy, or even the upcoming novel immunotherapies.

Through the systematical review of MDSC and its critical role in immune-microenvironment and immunotherapy, we are a step closer to discovering a more detailed and comprehensive standard of cancer immunotherapy. Accumulating high-quality researches on MDSC are underway and will constitute a further step toward a decisive combination strategy that drives cancer immunotherapy to a new era.

\section{Abbreviations}

MDSC: Myeloid-derived suppressor cell; Treg: Regulatory T cell; TAM: Tumorassociated macrophage; Th2: Type 2 helper CD4+ T cell; NK cell: Natural killer cell; PMN-MDSC: Polymorphonuclear MDSC; M-MDSC: Monocytic MDSC; PBMC: Peripheral blood mononuclear cell; EMT: Epithelial-mesenchymal transition; HCC: hepatocellular cancer; VEGF: Vascular endothelial growth factor; PGE2: Prostaglandin E2; ACT: Adoptive T-cell immunotherapy; CRC: Colorectal cancer; ROS: Reactive oxygen species; PD-1: Programmed cell death protein 1; PD-L1: Programmed cell death protein ligand-1; NO: Nitric oxide; EOC: Epithelial ovarian cancer; HGF: Hepatocyte growth factor; BMSC: Bone marrow stem cell; DFS: Disease free survival; ESCC: Esophageal squamous cell carcinoma; NSCLC: Non-small cell lung cancer; HNSCC: Head and neck squamous cell carcinoma; FDA: Food and drug administration; CSCC: Cutaneous squamous cell carcinoma; OS: Overall survival; CAR$\mathrm{T}$ : Chimeric antigen receptor T-cell; ICl: Immune checkpoint inhibitor; TLR: Toll-like receptor; DC: Dendritic cell; COX-2: Cyclooxygenase 2;
TKI: Tyrosine kinase inhibitor; ATRA: All-trans retinoic acid; CTL: Cytotoxic T lymphocyte

\section{Supplementary Information}

The online version contains supplementary material available at https://doi. org/10.1186/s40364-021-00333-5.

Additional file 1: Supplementary Table 1. Prognostic association of MDSCs and tumors. Supplementary Table 2. The association of MDSCs and response of immunotherapies.

Acknowledgments

Not applicable.

Authors' contributions

ZN.H. and RY.L. drafted the manuscript. YY.W. and SY.L. finished the searching of data for article. ZQ.H. and ZY.H. supervised and revised the manuscript. Z.H. and R.L. share first authorship, the order in which they are listed was determined by workload. The author(s) read and approved the final manuscript.

\section{Funding}

This work was funded by the National Science Foundation of China (81974414, 81772788, 81873430)

Availability of data and materials

Not applicable.

\section{Declarations}

Ethics approval and consent to participate

Not applicable.

Consent for publication

Not applicable.

\section{Competing interests}

The authors have no conflicts of interest to declare.

\section{Author details}

${ }^{1}$ Department of Neurosurgery, Beijing TianTan Hospital, Capital Medical University, Beijing, China. ${ }^{2}$ Department of Obstetrics and Gynecology, Tongji Hospital, Tongji Medical College, Huazhong University of Science and Technology, Wuhan 430030, Hubei, China. ${ }^{3}$ Department of Gynecology and Oncology, National Cancer Center/Cancer Hospital, Chinese Academy of Medical Sciences and Peking Union Medical College, Beijing, China.

${ }^{4}$ Department of Hematology, Tongji Hospital, Tongji Medical College, Huazhong University of Science and Technology, Wuhan 430030, Hubei, China.

Received: 17 August 2021 Accepted: 26 September 2021 Published online: 24 October 2021

\section{References}

1. Hodi FS, O'Day SJ, McDermott DF, Weber RW, Sosman JA, Haanen JB, et al. Improved survival with ipilimumab in patients with metastatic melanoma. N Engl J Med. 2010;363(8):711-23.

2. Brahmer JR, Tykodi SS, Chow LQ, Hwu WJ, Topalian SL, Hwu P, et al. Safety and activity of anti-PD-L1 antibody in patients with advanced cancer. N England J Med. 2012;366(26):2455-65

3. Hanahan D, Coussens LM. Accessories to the crime: functions of cells recruited to the tumor microenvironment. Cancer Cell. 2012;21(3):30922.

4. Fernández A, Oliver L, Alvarez R, Fernández LE, Lee KP, Mesa C. Adjuvants and myeloid-derived suppressor cells: enemies or allies in therapeutic cancer vaccination. Hum Vaccin Immunother. 2014;10(11):3251-60.

5. Gabrilovich DI, Bronte V, Chen SH, Colombo MP, Ochoa A, OstrandRosenberg $\mathrm{S}$, et al. The terminology issue for myeloid-derived suppressor cells. Cancer Res. 2007;67(1):425 author reply 426. 
6. Solito S, Marigo I, Pinton L, Damuzzo V, Mandruzzato S, Bronte V. Myeloidderived suppressor cell heterogeneity in human cancers. Ann N Y Acad Sci. 2014;1319:47-65.

7. Jiang J, Guo W, Liang X. Phenotypes, accumulation, and functions of myeloid-derived suppressor cells and associated treatment strategies in cancer patients. Hum Immunol. 2014;75(11):1128-37.

8. Bronte V, Brandau S, Chen SH, Colombo MP, Frey AB, Greten TF, et al. Recommendations for myeloid-derived suppressor cell nomenclature and characterization standards. Nat Commun. 2016;7:12150.

9. Cassetta L, Baekkevold ES, Brandau S, Bujko A, Cassatella MA, Dorhoi A, et al. Deciphering myeloid-derived suppressor cells: isolation and markers in humans, mice and non-human primates. Cancer Immunol Immunother. 2019;68(4):687-97.

10. Bruger AM, Dorhoi A, Esendagli G, Barczyk-Kahlert K, van der Bruggen P, Lipoldova $M$, et al. How to measure the immunosuppressive activity of MDSC: assays, problems and potential solutions. Cancer Immunol Immunother. 2019;68(4):631-44

11. De Cicco P, Ercolano G, lanaro A. The new era of cancer immunotherapy: targeting myeloid-derived suppressor cells to overcome immune evasion. Front Immunol. 2020;11:1680.

12. Yang Z, Guo J, Weng L, Tang W, Jin S, Ma W. Myeloid-derived suppressor cellsnew and exciting players in lung cancer. J hematol Oncol. 2020;13(1):10.

13. Trovato R, Fiore A, Sartori $S$, Canè $S$, Giugno $R$, Cascione $L$, et al. Immunosuppression by monocytic myeloid-derived suppressor cells in patients with pancreatic ductal carcinoma is orchestrated by STAT3. J Immunother Cancer. 2019;7(1):255.

14. Walter S, Weinschenk T, Stenzl A, Zdrojowy R, Pluzanska A, Szczylik C, et al. Multipeptide immune response to cancer vaccine IMA901 after single-dose cyclophosphamide associates with longer patient survival. Nat Med. 2012; 18(8):1254-61.

15. Lang S, Bruderek K, Kaspar C, Höing B, Kanaan O, Dominas N, et al. Clinical relevance and suppressive capacity of human myeloid-derived suppressor cell subsets. Clin Cancer Res. 2018;24(19):4834-44.

16. Vetsika EK, Koinis F, Gioulbasani M, Aggouraki D, Koutoulaki A, Skalidaki E, et al. A circulating subpopulation of monocytic myeloid-derived suppressor cells as an independent prognostic/predictive factor in untreated non-small lung cancer patients. J Immunol Res. 2014;2014:659294.

17. Mandruzzato S, Solito S, Falisi E, Francescato S, Chiarion-Sileni V, Mocellin S, et al. IL4Ralpha+ myeloid-derived suppressor cell expansion in cancer patients. J Immunol. 2009;182(10):6562-8.

18. Yu J, Du W, Yan F, Wang Y, Li H, Cao S, et al. Myeloid-derived suppressor cells suppress antitumor immune responses through IDO expression and correlate with lymph node metastasis in patients with breast cancer. J Immunol. 2013;190(7):3783-97.

19. Chun E, Lavoie S, Michaud M, Gallini CA, Kim J, Soucy G, et al. CCL2 promotes colorectal carcinogenesis by enhancing polymorphonuclear myeloid-derived suppressor cell population and function. Cell Rep. 2015;12(2):244-57.

20. Inamoto $S$, Itatani $Y$, Yamamoto $T$, Minamiguchi $S$, Hirai $H$, Iwamoto $M$, et al. Loss of SMAD4 promotes colorectal cancer progression by accumulation of myeloid-derived suppressor cells through the CCL15-CCR1 chemokine axis. Clin Cancer Res. 2016;22(2):492-501.

21. Li B, Zhang S, Huang N, Chen H, Wang P, Yang J, et al. CCL9/CCR1 induces myeloid-derived suppressor cell recruitment to the spleen in a murine $\mathrm{H} 22$ orthotopic hepatoma model. Oncol Rep. 2019;41(1):608-18.

22. Katoh H, Wang D, Daikoku T, Sun H, Dey SK, Dubois RN. CXCR2-expressing myeloid-derived suppressor cells are essential to promote colitis-associated tumorigenesis. Cancer Cell. 2013;24(5):631-44.

23. Taki M, Abiko K, Baba T, Hamanishi J, Yamaguchi K, Murakami R, et al. Snail promotes ovarian cancer progression by recruiting myeloid-derived suppressor cells via CXCR2 ligand upregulation. Nat Commun. 2018;9(1):1685.

24. Li YM, Liu ZY, Wang JC, Yu JM, Li ZC, Yang HJ, et al. Receptor-interacting protein kinase 3 deficiency recruits myeloid-derived suppressor cells to hepatocellular carcinoma through the chemokine (C-X-C Motif) ligand 1chemokine (C-X-C Motif) receptor 2 axis. Hepatology. 2019;70(5):1564-81.

25. Liao W, Overman MJ, Boutin AT, Shang X, Zhao D, Dey P, et al. KRAS-IRF2 axis drives immune suppression and immune therapy resistance in colorectal cancer. Cancer Cell. 2019;35(4):559-72 e557.

26. Xu Y, Fang F, Jiao H, Zheng $X$, Huang L, Yi X, et al. Activated hepatic stellate cells regulate MDSC migration through the SDF-1/CXCR4 axis in an orthotopic mouse model of hepatocellular carcinoma. Cancer Immunol Immunother. 2019;68(12):1959-69.
27. Jiang K, Li J, Zhang J, Wang L, Zhang Q, Ge J, et al. SDF-1/CXCR4 axis facilitates myeloid-derived suppressor cells accumulation in osteosarcoma microenvironment and blunts the response to anti-PD-1 therapy. Int Immunopharmacol. 2019;75:105818.

28. Alfaro C, Teijeira A, Oñate C, Pérez G, Sanmamed MF, Andueza MP, et al. Tumor-produced interleukin-8 attracts human myeloid-derived suppressor cells and elicits extrusion of neutrophil extracellular traps (NETs). Clin Cancer Res. 2016;22(15):3924-36.

29. Itatani Y, Kawada K, Fujishita T, Kakizaki F, Hirai H, Matsumoto T, et al. Loss of SMAD4 from colorectal cancer cells promotes CCL15 expression to recruit CCR1+ myeloid cells and facilitate liver metastasis. Gastroenterology. 2013;145(5):1064-75 e1011.

30. Chiu DK, Xu IM, Lai RK, Tse AP, Wei LL, Koh HY, et al. Hypoxia induces myeloid-derived suppressor cell recruitment to hepatocellular carcinoma through chemokine (C-C motif) ligand 26. Hepatology. 2016;64(3):797-813.

31. Horikawa N, Abiko K, Matsumura N, Hamanishi J, Baba T, Yamaguchi K, et al. Expression of vascular endothelial growth factor in ovarian cancer inhibits tumor immunity through the accumulation of myeloid-derived suppressor cells. Clin Cancer Res. 2017;23(2):587-99.

32. Chen JY, Lai YS, Chu PY, Chan SH, Wang LH, Hung WC. Cancer-derived VEGF-C increases chemokine production in lymphatic endothelial cells to promote CXCR2-dependent cancer invasion and MDSC recruitment. Cancers (Basel). 2019;11(8):1120.

33. Secondini C, Coquoz O, Spagnuolo L, Spinetti T, Peyvandi S, Ciarloni L, et al. Arginase inhibition suppresses lung metastasis in the 4T1 breast cancer model independently of the immunomodulatory and anti-metastatic effects of VEGFR-2 blockade. Oncoimmunology. 2017;6(6):e1316437.

34. Zhang Y, Liu Q, Zhang M, Yu Y, Liu X, Cao X. Fas signal promotes lung cancer growth by recruiting myeloid-derived suppressor cells via cancer cell-derived PGE2. J Immunol. 2009;182(6):3801-8.

35. Obermajer N, Muthuswamy R, Odunsi K, Edwards RP, Kalinski P. PGE (2)-induced CXCL12 production and CXCR4 expression controls the accumulation of human MDSCs in ovarian cancer environment. Cancer Res. 2011;71(24):7463-70.

36. Guo B, Fu S, Zhang J, Liu B, Li Z. Targeting inflammasome/lL-1 pathways for cancer immunotherapy. Sci Rep. 2016;6:36107.

37. Ma S, Cheng Q, Cai Y, Gong H, Wu Y, Yu X, et al. IL-17A produced by gammadelta $T$ cells promotes tumor growth in hepatocellular carcinoma. Cancer Res. 2014;74(7):1969-82.

38. Douguet $L$, Bod L, Lengagne $R$, Labarthe $L$, Kato M, Avril MF, et al. Nitric oxide synthase 2 is involved in the pro-tumorigenic potential of gammadelta17 T cells in melanoma. Oncoimmunology. 2016;5(8):e1208878.

39. Liu Y, Lai L, Chen Q, Song Y, Xu S, Ma F, et al. MicroRNA-494 is required for the accumulation and functions of tumor-expanded myeloid-derived suppressor cells via targeting of PTEN. J Immunol. 2012;188(11):5500-10.

40. Sarkar S, Bristow CA, Dey P, Rai K, Perets R, Ramirez-Cardenas A, et al. PRKCl promotes immune suppression in ovarian cancer. Genes Dev. 2017;31(11): 1109-21.

41. Karasaki T, Nagayama K, Kuwano H, Nitadori Jl, Sato M, Anraku M, et al. An immunogram for the cancer-immunity cycle: towards personalized immunotherapy of lung cancer. J Thorac Oncol. 2017;12(5):791-803.

42. Hosoi A, Matsushita H, Shimizu K, Fujii S-i, Ueha S, Abe J, et al. Adoptive cytotoxic T lymphocyte therapy triggers a counter-regulatory immunosuppressive mechanism via recruitment of myeloid-derived suppressor cells. Int J Cancer. 2014;134(8):1810-22.

43. Dan I, Roberto C, Diana L. UPA and UPA-receptor are involved in cancerassociated myeloid-derived suppressor cell accumulation. Anticancer Res. 2012;32(10):4263-70

44. Huang M, Wu R, Chen L, Peng Q, Li S, Zhang Y, et al. S100A9 regulates MDSCs-mediated immune suppression via the RAGE and TLR4 signaling pathways in colorectal carcinoma. Front Immunol. 2019;10:2243.

45. Beury DW, Carter KA, Nelson C, Sinha P, Hanson E, Nyandjo M, et al Myeloid-derived suppressor cell survival and function are regulated by the transcription factor Nrf2. J Immunol. 2016;196(8):3470-8.

46. Ostrand-Rosenberg S, Beury DW, Parker KH, Horn LA. Survival of the fittest: how myeloid-derived suppressor cells survive in the inhospitable tumor microenvironment. Cancer Immunol Immunother. 2020;69(2):215-21.

47. Serafini P, Mgebroff S, Noonan K, Borrello I. Myeloid-derived suppressor cells promote cross-tolerance in B-cell lymphoma by expanding regulatory $\mathrm{T}$ cells. Cancer Res. 2008;68(13):5439-49.

48. Ghiringhelli F, Puig PE, Roux S, Parcellier A, Schmitt E, Solary E, et al. Tumor cells convert immature myeloid dendritic cells into TGF-beta-secreting cells 
inducing CD4+CD25+ regulatory T cell proliferation. J Exp Med. 2005;202(7): 919-29.

49. Huang B, Pan PY, Li Q, Sato Al, Levy DE, Bromberg J, et al. Gr-1+CD115+ immature myeloid suppressor cells mediate the development of tumorinduced T regulatory cells and T-cell anergy in tumor-bearing host. Cancer Res. 2006;66(2):1123-31.

50. Lee CR, Kwak Y, Yang T, Han JH, Park SH, Ye MB, et al. Myeloid-derived suppressor cells are controlled by regulatory T cells via TGF- $\beta$ during murine colitis. Cell Rep. 2016;17(12):3219-32.

51. Shen M, Wang J, Yu W, Zhang C, Liu M, Wang K, et al. A novel MDSCinduced PD-1(-)PD-L1(+) B-cell subset in breast tumor microenvironment possesses immuno-suppressive properties. Oncoimmunology. 2018;7(4): e1413520.

52. Lee-Chang C, Rashidi A, Miska J, Zhang P, Pituch KC, Hou D, et al. Myeloidderived suppressive cells promote $B$ cell-mediated immunosuppression via transfer of PD-L1 in glioblastoma. Cancer Immunol Res. 2019;7(12):1928-43.

53. Kusmartsev S, Nefedova Y, Yoder D, Gabrilovich DI. Antigen-specific inhibition of CD8+ T cell response by immature myeloid cells in cancer is mediated by reactive oxygen species. J Immunol. 2004;172(2):989-99.

54. Schmielau J, Finn OJ. Activated granulocytes and granulocyte-derived hydrogen peroxide are the underlying mechanism of suppression of t-cell function in advanced cancer patients. Cancer Res. 2001;61(12):4756-60.

55. Mazzoni A, Bronte V, Visintin A, Spitzer JH, Apolloni E, Serafini P, et al. Myeloid suppressor lines inhibit T cell responses by an NO-dependent mechanism. J Immunol. 2002;168(2):689-95.

56. Movahedi K, Guilliams M, Van den Bossche J, Van den Bergh R, Gysemans C, Beschin A, et al. Identification of discrete tumor-induced myeloid-derived suppressor cell subpopulations with distinct T cell-suppressive activity. Blood. 2008;111(8):4233-44.

57. Dufait I, Pardo J, Escors D, De Vlaeminck Y, Jiang H, Keyaerts M, et al. Perforin and granzyme $B$ expressed by murine myeloid-derived suppressor cells: a study on their role in outgrowth of cancer cells. Cancers (Basel). 2019;11(6):808

58. Schouppe E, Van Overmeire E, Laoui D, Keirsse J, Van Ginderachter JA. Modulation of CD8(+) T-cell activation events by monocytic and granulocytic myeloid-derived suppressor cells. Immunobiology. 2013; 218(11):1385-91.

59. Jiang M, Chen J, Zhang W, Zhang R, Ye Y, Liu P, et al. Interleukin-6 transsignaling pathway promotes immunosuppressive myeloid-derived suppressor cells via suppression of suppressor of cytokine signaling 3 in breast cancer. Front Immunol. 2017;8:1840.

60. Sangaletti S, Talarico G, Chiodoni C, Cappetti B, Botti L, Portararo P, et al. SPARC is a new myeloid-derived suppressor cell marker licensing suppressive activities. Front Immunol. 2019:10:1369.

61. Abdissa K, Nerlich A, Beineke A, Ruangkiattikul N, Pawar V, Heise U, et al. presence of infected Gr-1(int)CD11b(hi)CD11 (int) monocytic myeloid derived suppressor cells subverts T cell response and is associated with impaired dendritic cell function in mycobacterium avium-infected mice. Front Immunol. 2018;9:2317.

62. Ohl K, Tenbrock K. Reactive oxygen species as regulators of MDSC-mediated immune suppression. Front Immunol. 2018;9:2499.

63. Li J, Wang L, Chen X, Li L, Li Y, Ping Y, et al. CD39/CD73 upregulation on myeloid-derived suppressor cells via TGF-beta-mTOR-HIF-1 signaling in patients with non-small cell lung cancer. Oncoimmunology. 2017;6(6): e1320011.

64. Cekic C, Day YJ, Sag D, Linden J. Myeloid expression of adenosine A2A receptor suppresses T and NK cell responses in the solid tumor microenvironment. Cancer Res. 2014;74(24):7250-9.

65. Deng J, Li J, Sarde A, Lines JL, Lee YC, Qian DC, et al. Hypoxia-induced VISTA promotes the suppressive function of myeloid-derived suppressor cells in the tumor microenvironment. Cancer Immunol Res. 2019;7(7):1079-90.

66. Noman MZ, Desantis G, Janji B, Hasmim M, Karray S, Dessen P, et al. PD-L1 is a novel direct target of HIF-1alpha, and its blockade under hypoxia enhanced MDSC-mediated T cell activation. J Exp Med. 2014;211(5):781-90.

67. Tsukamoto H, Nishikata R, Senju S, Nishimura Y. Myeloid-derived suppressor cells attenuate $\mathrm{TH} 1$ development through IL-6 production to promote tumor progression. Cancer Immunol Res. 2013;1 (1):64-76.

68. Hoechst B, Voigtlaender T, Ormandy L, Gamrekelashvili J, Zhao F, Wedemeyer $\mathrm{H}$, et al. Myeloid derived suppressor cells inhibit natural killer cells in patients with hepatocellular carcinoma via the NKp30 receptor. Hepatology. 2009;50(3):799-807.
69. Goh CC, Roggerson KM, Lee HC, Golden-Mason L, Rosen HR, Hahn YS Hepatitis C virus-induced myeloid-derived suppressor cells suppress NK cell IFN-gamma production by altering cellular metabolism via arginase-1. J Immunol. 2016;196(5):2283-92.

70. Mao Y, Sarhan D, Steven A, Seliger B, Kiessling R, Lundqvist A. Inhibition of tumor-derived prostaglandin-e2 blocks the induction of myeloid-derived suppressor cells and recovers natural killer cell activity. Clin Cancer Res. 2014;20(15):4096-106.

71. Wang Y, Schafer CC, Hough KP, Tousif S, Duncan SR, Kearney JF, et al. Myeloid-derived suppressor cells impair B cell responses in lung cancer through IL-7 and STAT5. J Immunol. 2018;201(1):278-95.

72. Tarcic O, Pateras IS, Cooks T, Shema E, Kanterman J, Ashkenazi H, et al. RNF20 links histone H2B ubiquitylation with inflammation and inflammation-associated cancer. Cell Rep. 2016;14(6):1462-76.

73. Bi L, Gojestani S, Wu W, Hsu YM, Zhu J, Ariizumi K, et al. CARD9 mediates dectin-2-induced IkappaBalpha kinase ubiquitination leading to activation of NF-kappaB in response to stimulation by the hyphal form of Candida albicans. J Biol Chem. 2010;285(34):25969-77.

74. Wang T, Fan C, Yao A, Xu X, Zheng G, You Y, et al. The Adaptor Protein CARD9 Protects against Colon Cancer by Restricting Mycobiota-Mediated Expansion of Myeloid-Derived Suppressor Cells. Immunity. 2018:49(3):504-14 e504.

75. Harusato A, Viennois E, Etienne-Mesmin L, Matsuyama S, Abo H, Osuka S, et al. Early-Life Microbiota Exposure Restricts Myeloid-Derived Suppressor Cell-Driven Colonic Tumorigenesis. Cancer Immunol Res. 2019;7(4):544-51.

76. Mohammed L, John K, Chunwan L, Priscilla R, Wei X, Dafeng Y, et al. Myeloid-Derived Suppressor Cells Produce IL-10 to Elicit DNMT3bDependent IRF8 Silencing to Promote Colitis-Associated Colon Tumorigenesis. Cell Rep. 2018;25(11):3036-46.e6.

77. Yan G, Zhao H, Zhang Q, Zhou Y, Wu L, Lei J, et al. A RIPK3-PGE (2) Circuit Mediates Myeloid-Derived Suppressor Cell-Potentiated Colorectal Carcinogenesis. Cancer Res. 2018;78(19):5586-99.

78. Ke Z, Wang C, WU T, Wang W, Yang Y, Dai Y. PAR2 deficiency enhances myeloid cell-mediated immunosuppression and promotes colitis-associated tumorigenesis. Cancer Lett. 2020;469:437-46.

79. Wen L, Mu W, Lu H, Wang X, Fang J, Jia Y, et al. Porphyromonas gingivalis Promotes Oral Squamous Cell Carcinoma Progression in an Immune Microenvironment. J Dent Res. 2020;99(6):666-75.

80. Grivennikov S, Karin E, Terzic J, Mucida D, Yu GY, Vallabhapurapu S, et al. IL6 and Stat3 are required for survival of intestinal epithelial cells and development of colitis-associated cancer. Cancer Cell. 2009;15(2):103-13.

81. Zhang Q, Ma C, Duan Y, Heinrich B, Rosato U, Diggs LP, et al. Gut microbiome directs hepatocytes to recruit MDSC and promote cholangiocarcinoma. Cancer Discov. 2020;11(5):1248-67.

82. Chen X, Eksioglu EA, Zhou J, Zhang L, Djeu J, Fortenbery N, et al. Induction of myelodysplasia by myeloid-derived suppressor cells. J Clin Invest. 2013; 123(11):4595-611.

83. Wang Y, Yin K, Tian J, Xia X, Ma J, Tang X, et al. Granulocytic myeloidderived suppressor cells promote the stemness of colorectal cancer cells through exosomal S100A9. Adv Sci (Weinh). 2019;6(18):1901278.

84. Li X, Wang J, Wu W, Gao H, Liu N, Zhan G, et al. Myeloid-derived suppressor cells promote epithelial ovarian cancer cell stemness by inducing the CSF2/ p-STAT3 signalling pathway. Febs J. 2020;287(23):5218-35.

85. Xu Z, Li L, Qian Y, Song Y, Qin L, Duan Y, et al. Upregulation of IL-6 in CUL4B-deficient myeloid-derived suppressive cells increases the aggressiveness of cancer cells. Oncogene. 2019;38(30):5860-72.

86. Ai L, Mu S, Sun C, Fan F, Yan H, Qin Y, et al. Myeloid-derived suppressor cells endow stem-like qualities to multiple myeloma cells by inducing piRNA-823 expression and DNMT3B activation. Mol Cancer. 2019;18(1):88.

87. Merighi S, Benini A, Mirandola P, Gessi S, Varani K, Simioni C, et al. Caffeine inhibits adenosine-induced accumulation of hypoxia-inducible factor1alpha, vascular endothelial growth factor, and interleukin-8 expression in hypoxic human colon cancer cells. Mol Pharmacol. 2007;72(2):395-406.

88. Chen L, Xiong L, Hong S, Li J, Huo Z, Li Y, et al. Circulating myeloid-derived suppressor cells facilitate invasion of thyroid cancer cells by repressing miR486-3p. J Clin Endocrinol Metab. 2020;105(8):dgaa344.

89. Li YD, Lamano JB, Lamano JB, Quaggin-Smith J, Veliceasa D, Kaur G, et al. Tumor-induced peripheral immunosuppression promotes brain metastasis in patients with non-small cell lung cancer. Cancer Immunol Immunother. 2019;68(9):1501-13.

90. Bosiljcic M, Cederberg RA, Hamilton MJ, LePard NE, Harbourne BT, Collier JL, et al. Targeting myeloid-derived suppressor cells in combination with 
primary mammary tumor resection reduces metastatic growth in the lungs. Breast Cancer Res. 2019;21(1):103.

91. Sprouse ML, Welte T, Boral D, Liu HN, Yin W, Vishnoi M, et al. PMN-MDSCs enhance CTC metastatic properties through reciprocal interactions via ROS/ Notch/Nodal signaling. Int J Mol Sci. 2019;20(8):1916.

92. Wang D, Sun H, Wei J, Cen B, DuBois RN. CXCL1 is critical for premetastatic niche formation and metastasis in colorectal cancer. Cancer Res. 2017; 77(13):3655-65.

93. Sasano T, Mabuchi S, Kozasa K, Kuroda H, Kawano M, Takahashi R, et al. The highly metastatic nature of uterine cervical/endometrial cancer displaying tumor-related leukocytosis: clinical and preclinical investigations. Clin Cancer Res. 2018;24(16):4018-29.

94. Hsu YL, Yen MC, Chang WA, Tsai PH, Pan YC, Liao SH, et al. CXCL17-derived $\mathrm{CD} 11 \mathrm{~b}(+) \mathrm{Gr}-1(+)$ myeloid-derived suppressor cells contribute to lung metastasis of breast cancer through platelet-derived growth factor-BB. Breast Cancer Res. 2019;21(1):23.

95. Chafe SC, Lou Y, Sceneay J, Vallejo M, Hamilton MJ, McDonald PC, et al. Carbonic anhydrase IX promotes myeloid-derived suppressor cell mobilization and establishment of a metastatic niche by stimulating G-CSF production. Cancer Res. 2015;75(6):996-1008

96. Kumar S, Wilkes DW, Samuel N, Blanco MA, Nayak A, Alicea-Torres K, et al. $\Delta$ Np63-driven recruitment of myeloid-derived suppressor cells promotes metastasis in triple-negative breast cancer. J Clin Invest. 2018;128(11):5095-109.

97. Lin Q, Ren L, Jian M, Xu P, Li J, Zheng P, et al. The mechanism of the premetastatic niche facilitating colorectal cancer liver metastasis generated from myeloid-derived suppressor cells induced by the S1PR1-STAT3 signaling pathway. Cell Death Dis. 2019;10(10):693.

98. Wei L, Zhang X, Wang J, Ye Q, Zheng X, Peng Q, et al. Lactoferrin deficiency induces a pro-metastatic tumor microenvironment through recruiting myeloid-derived suppressor cells in mice. Oncogene. 2020;39(1):122-35.

99. Zhang J, Han X, Shi H, Gao Y, Qiao X, Li H, et al. Lung resided monocytic myeloid-derived suppressor cells contribute to premetastatic niche formation by enhancing MMP-9 expression. Mol Cell Probes. 2020;50: 101498.

100. Ghouse SM, Vadrevu SK, Manne S, Reese B, Patel J, Patel B, et al. Therapeutic targeting of vasculature in the premetastatic and metastatic niches reduces lung metastasis. J Immunol. 2020;204(4):990-1000.

101. Toh B, Wang X, Keeble J, Sim WJ, Khoo K, Wong WC, et al. Mesenchymal transition and dissemination of cancer cells is driven by myeloid-derived suppressor cells infiltrating the primary tumor. PLoS Biol. 2011;9(9):e1001162.

102. Luo A, Meng M, Wang G, Han R, Zhang $Y$, Jing $X$, et al. Myeloidderived suppressor cells recruited by chemokine (C-C Motif) ligand 3 promote the progression of breast cancer via phosphoinositide 3kinase-protein kinase b-mammalian target of rapamycin signaling. J Breast Cancer. 2020;23(2):141-61.

103. Ma X, Wang M, Yin T, Zhao Y, Wei X. Myeloid-derived suppressor cells promote metastasis in breast cancer after the stress of operative removal of the primary cancer. Front Oncol. 2019;9:855.

104. Sai B, Dai Y, Fan S, Wang F, Wang L, Li Z, et al. Cancer-educated mesenchymal stem cells promote the survival of cancer cells at primary and distant metastatic sites via the expansion of bone marrow-derived-PMNMDSCs. Cell Death Dis. 2019;10(12):941.

105. Wang $T$, Jing $B, X u D$, Liao $Y$, Song $H$, Sun B, et al. PTGES/PGE (2) signaling links immunosuppression and lung metastasis in Gprc5a-knockout mouse model. Oncogene. 2020;39(15):3179-94.

106. Jing B, Wang T, Sun B, Xu J, Xu D, Liao Y, et al. IL6/STAT3 signaling orchestrates premetastatic niche formation and immunosuppressive traits in lung. Cancer Res. 2020;80(4):784-97.

107. Takahashi R, Amano H, Ito Y, Eshima K, Satoh T, Iwamura M, et al. Microsomal prostaglandin E synthase-1 promotes lung metastasis via SDF-1/ CXCR4-mediated recruitment of CD11b(+)Gr1(+)MDSCs from bone marrow. Biomed Pharmacother. 2020;121:109581.

108. lida-Norita R, Kawamura M, Suzuki Y, Hamada S, Masamune A, Furukawa T, et al. Vasohibin-2 plays an essential role in metastasis of pancreatic ductal adenocarcinoma. Cancer Sci. 2019;110(7):2296-308.

109. Dajon M, Iribarren K, Petitprez F, Marmier S, Lupo A, Gillard M, et al. Toll like receptor 7 expressed by malignant cells promotes tumor progression and metastasis through the recruitment of myeloid derived suppressor cells. Oncoimmunology. 2019;8(1):e1505174.

110. Gabitass RF, Annels NE, Stocken DD, Pandha HA, Middleton GW. Elevated myeloid-derived suppressor cells in pancreatic, esophageal and gastric cancer are an independent prognostic factor and are associated with significant elevation of the Th2 cytokine interleukin-13. Cancer Immuno Immunother. 2011;60(10):1419-30.

111. Wang L, Chang EW, Wong SC, Ong SM, Chong DQ, Ling KL. Increased myeloid-derived suppressor cells in gastric cancer correlate with cancer stage and plasma S100A8/A9 proinflammatory proteins. J Immunol. 2013; 190(2):794-804.

112. Zhang Y, Xie J, Han G, Dong B, Zhang Y, Zhang J. Detection and clinical significance of myeloid-derived suppressor cells in peripheral blood of patients with rectal carcinoma. Zhonghua Wei Chang Wai Ke Za Zhi. 2017; 20(7):798-802

113. Yuan L, Yuan P, Du J, Chen G, Wan X, Li Z, et al. Relationship of preoperative and postoperative myeloid-derived suppressor cells percentage with the prognosis in rectal cancer patients. Zhonghua Wei Chang Wai Ke Za Zhi. 2015;18(11):1139-43.

114. Solito S, Falisi E, Diaz-Montero CM, Doni A, Pinton L, Rosato A, et al. A human promyelocytic-like population is responsible for the immune suppression mediated by myeloid-derived suppressor cells. Blood. 2011; 118(8):2254-65

115. Wang D, An G, Xie S, Yao Y, Feng G. The clinical and prognostic significance of CD14(+)HLA-DR(-/low) myeloid-derived suppressor cells in hepatocellular carcinoma patients receiving radiotherapy. Tumour Biol. 2016;37(8):10427-33.

116. Zhou J, Liu M, Sun H, Feng Y, Xu L, Chan AWH, et al. Hepatoma-intrinsic CCRK inhibition diminishes myeloid-derived suppressor cell immunosuppression and enhances immune-checkpoint blockade efficacy. Gut. 2018;67(5):931-44

117. Deng Y, Cheng J, Fu B, Liu W, Chen G, Zhang Q, et al. Hepatic carcinoma-associated fibroblasts enhance immune suppression by facilitating the generation of myeloidderived suppressor cells. Oncogene. 2017;36(8):1090-101.

118. Zhang H, Li ZL, Ye SB, Ouyang LY, Chen YS, He J, et al. Myeloid-derived suppressor cells inhibit T cell proliferation in human extranodal NK/T cell lymphoma: a novel prognostic indicator. Cancer Immunol Immunother. 2015;64(12):1587-99.

119. Chevolet I, Speeckaert R, Schreuer M, Neyns B, Krysko O, Bachert C, et al. Clinical significance of plasmacytoid dendritic cells and myeloid-derived suppressor cells in melanoma. J Transl Med. 2015;13:9.

120. Sade-Feldman M, Kanterman J, Klieger $Y$, Ish-Shalom E, Olga M, Saragovi A, et al. Clinical significance of circulating CD33+CD11b+HLA-DR- myeloid cells in patients with stage IV melanoma treated with ipilimumab. Clin Cancer Res. 2016;22(23):5661-72

121. Yang G, Shen W, Zhang Y, Liu M, Zhang L, Liu Q, et al. Accumulation of myeloid-derived suppressor cells (MDSCs) induced by low levels of IL-6 correlates with poor prognosis in bladder cancer. Oncotarget. 2017;8(24): 38378-88.

122. Mizukoshi E, Yamashita T, Arai K, Terashima T, Kitahara M, Nakagawa H, et al. Myeloid-derived suppressor cells correlate with patient outcomes in hepatic arterial infusion chemotherapy for hepatocellular carcinoma. Cancer Immunol Immunother. 2016;65(6):715-25.

123. Gao XH, Tian L, Wu J, Ma XL, Zhang CY, Zhou Y, et al. Circulating CD14(+) HLA-DR(-/low) myeloid-derived suppressor cells predicted early recurrence of hepatocellular carcinoma after surgery. Hepatol Res. 2017;47(10):1061-71.

124. Santegoets SJ, Stam AG, Lougheed SM, Gall H, Jooss K, Sacks N, et al. Myeloid derived suppressor and dendritic cell subsets are related to clinical outcome in prostate cancer patients treated with prostate GVAX and ipilimumab. J Immunother Cancer. 2014;2:31.

125. Huang H, Zhang G, Li G, Ma H, Zhang X. Circulating CD14(+)HLA-DR(-/low) myeloid-derived suppressor cell is an indicator of poor prognosis in patients with ESCC. Tumour Biol. 2015;36(10):7987-96.

126. Weide B, Martens A, Zelba H, Stutz C, Derhovanessian E, Di Giacomo AM, et al. Myeloid-derived suppressor cells predict survival of patients with advanced melanoma: comparison with regulatory T cells and NY-ESO-1- or melan-A-specific T cells. Clin Cancer Res. 2014;20(6):1601-9.

127. Jiang H, Gebhardt C, Umansky L, Beckhove P, Schulze TJ, Utikal J, et al. Elevated chronic inflammatory factors and myeloid-derived suppressor cells indicate poor prognosis in advanced melanoma patients. Int J Cancer. 2015; 136(10):2352-60.

128. Martens A, Wistuba-Hamprecht K, Geukes Foppen M, Yuan J, Postow MA, Wong $P$, et al. Baseline peripheral blood biomarkers associated with clinical outcome of advanced melanoma patients treated with ipilimumab. Clin Cancer Res. 2016;22(12):2908-18. 
129. Weber J, Gibney G, Kudchadkar R, Yu B, Cheng P, Martinez AJ, et al. Phase I/ II study of metastatic melanoma patients treated with nivolumab who had progressed after ipilimumab. Cancer Immunol Res. 2016;4(4):345-53.

130. de Coaña YP, Wolodarski M, Poschke I, Yoshimoto $Y$, Yang Y, Nyström M, et al. Ipilimumab treatment decreases monocytic MDSCs and increases CD8 effector memory T cells in long-term survivors with advanced melanoma. Oncotarget. 2017:8(13):21539-53.

131. Tian T, Gu X, Zhang B, Liu Y, Yuan C, Shao L, et al. Increased circulating CD14(+)HLA-DR-/low myeloid-derived suppressor cells are associated with poor prognosis in patients with small-cell lung cancer. Cancer Biomark. 2015;15(4):425-32.

132. de Goeje PL, Bezemer K, Heuvers ME, Dingemans AC, Groen HJ, Smit EF, et al. Immunoglobulin-like transcript 3 is expressed by myeloid-derived suppressor cells and correlates with survival in patients with non-small cell lung cancer. Oncoimmunology. 2015;4(7):e1014242.

133. Hansen GL, Gaudernack G, Brunsvig PF, Cvancarova M, Kyte JA. Immunological factors influencing clinical outcome in lung cancer patients after telomerase peptide vaccination. Cancer Immunol Immunother. 2015; 64(12):1609-21.

134. Horinaka A, Sakurai D, Ihara F, Makita Y, Kunii N, Motohashi S, et al. Invariant NKT cells are resistant to circulating CD15+ myeloid-derived suppressor cells in patients with head and neck cancer. Cancer Sci. 2016;107(3):207-16.

135. Mundy-Bosse BL, Young GS, Bauer T, Binkley E, Bloomston M, Bill MA, et al. Distinct myeloid suppressor cell subsets correlate with plasma IL-6 and IL-10 and reduced interferon-alpha signaling in $\mathrm{CD}^{+} \mathrm{T}$ cells from patients with Gl malignancy. Cancer Immunol Immunother. 2011;60(9):1269-79.

136. Bailur JK, Gueckel B, Derhovanessian E, Pawelec G. Presence of circulating Her2-reactive CD8 + T-cells is associated with lower frequencies of myeloidderived suppressor cells and regulatory T cells, and better survival in older breast cancer patients. Breast Cancer Res. 2015;17(1):34

137. Choi HS, Ha SY, Kim HM, Ahn SM, Kang MS, Kim KM, et al. The prognostic effects of tumor infiltrating regulatory $T$ cells and myeloid derived suppressor cells assessed by multicolor flow cytometry in gastric cancer patients. Oncotarget. 2016;7(7):7940-51.

138. Shoji H, Tada K, Kitano S, Nishimura T, Shimada Y, Nagashima K, et al. The peripheral immune status of granulocytic myeloid-derived suppressor cells correlates the survival in advanced gastric cancer patients receiving cisplatin-based chemotherapy. Oncotarget. 2017;8(56):95083-94.

139. Gonda K, Shibata M, Ohtake T, Matsumoto Y, Tachibana K, Abe N, et al. Myeloid-derived suppressor cells are increased and correlated with type 2 immune responses, malnutrition, inflammation, and poor prognosis in patients with breast cancer. Oncol Lett. 2017;14(2):1766-74.

140. Mizuno R, Kimura G, Fukasawa S, Ueda T, Kondo T, Hara H, et al. Angiogenic, inflammatory and immunologic markers in predicting response to sunitinib in metastatic renal cell carcinoma. Cancer Sci. 2017;108(9):1858-63.

141. Chi N, Tan Z, Ma K, Bao L, Yun Z. Increased circulating myeloid-derived suppressor cells correlate with cancer stages, interleukin-8 and -6 in prostate cancer. Int J Clin ExpMed. 2014;7(10):3181-92.

142. Zhang J, Xu X, Shi M, Chen Y, Yu D, Zhao C, et al. CD13(hi) Neutrophil-like myeloid-derived suppressor cells exert immune suppression through Arginase 1 expression in pancreatic ductal adenocarcinoma. Oncoimmunology. 2017;6(2):e1258504.

143. French JD, Kotnis GR, Said S, Raeburn CD, Mclntyre RC Jr, Klopper JP, et al. Programmed death-1+ T cells and regulatory $T$ cells are enriched in tumorinvolved lymph nodes and associated with aggressive features in papillary thyroid cancer. J Clin Endocrinol Metab. 2012;97(6):E934-43.

144. Severson JJ, Serracino HS, Mateescu V, Raeburn CD, Mclntyre RC Jr, Sams SB, et al. PD-1+Tim-3+ CD8+ T lymphocytes display varied degrees of functional exhaustion in patients with regionally metastatic differentiated thyroid cancer. Cancer Immunol Res. 2015;3(6):620-30.

145. Huse M. The T-cell-receptor signaling network. J Cell Sci. 2009;122(Pt 9):1269-73.

146. Chen L, Flies DB. Molecular mechanisms of T cell co-stimulation and coinhibition. Nat Rev Immunol. 2013;13(4):227-42.

147. Walker LS, Sansom DM. The emerging role of CTLA4 as a cell-extrinsic regulator of T cell responses. Nat Rev Immunol. 2011;11(12):852-63.

148. Amarnath S, Mangus CW, Wang JC, Wei F, He A, Kapoor V, et al. The PDL1PD1 axis converts human TH1 cells into regulatory T cells. Sci Transl Med. 2011;3(111):111ra120.

149. McDermott D, Haanen J, Chen TT, Lorigan P, O'Day S. Efficacy and safety of ipilimumab in metastatic melanoma patients surviving more than 2 years following treatment in a phase III trial (MDX010-20). Ann Oncol. 2013;24(10): 2694-8.

150. Weber JS, D'Angelo SP, Minor D, Hodi FS, Gutzmer R, Neyns B, et al. Nivolumab versus chemotherapy in patients with advanced melanoma who progressed after anti-CTLA-4 treatment (CheckMate 037): a randomised, controlled, open-label, phase 3 trial. Lancet Oncol. 2015;16(4):375-84.

151. Pico de Coaña Y, Wolodarski M, van der Haar Àvila I, Nakajima T, Rentouli S, Lundqvist A, et al. PD-1 checkpoint blockade in advanced melanoma patients: NK cells, monocytic subsets and host PD-L1 expression as predictive biomarker candidates. Oncoimmunology. 2020;9(1):1786888.

152. Limagne E, Richard C, Thibaudin M, Fumet JD, Truntzer C, Lagrange A, et al. Tim-3/galectin-9 pathway and MMDSC control primary and secondary resistances to PD-1 blockade in lung cancer patients. Oncoimmunology. 2019;8(4):e1564505.

153. Passaro A, Mancuso P, Gandini S, Spitaleri G, Labanca V, Guerini-Rocco E, et al. Gr-MDSC-linked asset as a potential immune biomarker in pretreated NSCLC receiving nivolumab as second-line therapy. Clin Transl Oncol. 2020; 22(4):603-11.

154. Youn Jl, Park SM, Park S, Kim G, Lee HJ, Son J, et al. Peripheral natural killer cells and myeloid-derived suppressor cells correlate with anti-PD-1 responses in non-small cell lung cancer. Sci Rep. 2020;10(1):9050.

155. Zhuo M, Chen H, Zhang T, Yang X, Zhong J, Wang Y, et al. The potential predictive value of circulating immune cell ratio and tumor marker in atezolizumab treated advanced non-small cell lung cancer patients. Cancer Biomark. 2018;22(3):467-76.

156. Karzai F, VanderWeele D, Madan RA, Owens H, Cordes LM, Hankin A, et al. Activity of durvalumab plus olaparib in metastatic castration-resistant prostate cancer in men with and without DNA damage repair mutations. J Immunother Cancer. 2018;6(1):141.

157. Jain MD, Zhao H, Wang $X$, Atkins $R$, Menges $M$, Reid $K$, et al. Tumor interferon signaling and suppressive myeloid cells associate with CAR T cell failure in large B cell lymphoma. Blood. 2021;137(19):2621-33.

158. Zhang J, Pang Y, Xie T, Zhu L. CXCR4 antagonism in combination with IDO1 inhibition weakens immune suppression and inhibits tumor growth in mouse breast cancer bone metastases. Onco Targets Ther. 2019;12:4985-92.

159. Lu Z, Zou J, Li S, Topper MJ, Tao Y, Zhang H, et al. Epigenetic therapy inhibits metastases by disrupting premetastatic niches. Nature. 2020; 579(7798):284-90.

160. Fleming V, Hu X, Weller C, Weber R, Groth C, Riester Z, et al. Melanoma Extracellular Vesicles Generate Immunosuppressive Myeloid Cells by Upregulating PD-L1 via TLR4 Signaling. Cancer Res. 2019;79(18):4715-28.

161. Xiang X, Liu Y, Zhuang X, Zhang S, Michalek S, Taylor DD, et al. TLR2mediated expansion of MDSCs is dependent on the source of tumor exosomes. Am J Pathol. 2010;177(4):1606-10.

162. Ichikawa M, Williams $R$, Wang L, Vogl T, Srikrishna G. S100A8/A9 activate key genes and pathways in colon tumor progression. Mol Cancer Res. 2011;9(2):133-48.

163. Cheng P, Corzo CA, Luetteke N, Yu B, Nagaraj S, Bui MM, et al. Inhibition of dendritic cell differentiation and accumulation of myeloid-derived suppressor cells in cancer is regulated by S100A9 protein. J Exp Med. 2008; 205(10):2235-49.

164. De Veirman K, De Beule N, Maes K, Menu E, De Bruyne E, De Raeve H, et al. Extracellular S100A9 Protein in Bone Marrow Supports Multiple Myeloma Survival by Stimulating Angiogenesis and Cytokine Secretion. Cancer Immunol Res. 2017;5(10):839-46.

165. Obermajer N, Muthuswamy R, Lesnock J, Edwards RP, Kalinski P. Positive feedback between PGE2 and COX2 redirects the differentiation of human dendritic cells toward stable myeloid-derived suppressor cells. Blood. 2011; 118(20):5498-505

166. Xu Y, Huang Y, Xu W, Zheng X, Yi X, Huang L, et al. Activated Hepatic Stellate Cells (HSCS) Exert Immunosuppressive Effects in Hepatocellular Carcinoma by Producing Complement C3. Onco Targets Ther. 2020;13: 1497-505.

167. Park JY, Pillinger MH, Abramson SB. Prostaglandin E2 synthesis and secretion: the role of PGE2 synthases. Clin Immunol. 2006;119(3):229-40.

168. Häusler SF, Del Barrio IM, Diessner J, Stein RG, Strohschein J, Hönig A, et al. Anti-CD39 and anti-CD73 antibodies A1 and 7G2 improve targeted therapy in ovarian cancer by blocking adenosine-dependent immune evasion. Am J Transl Res. 2014;6(2):129-39.

169. Perrot I, Michaud HA, Giraudon-Paoli M, Augier S, Docquier A, Gros L, et al. Blocking antibodies targeting the CD39/CD73 immunosuppressive pathway 
unleash immune responses in combination cancer therapies. Cell Rep. 2019; 27(8):2411-2425.e2419.

170. Lee CR, Lee W, Cho SK, Park SG. Characterization of multiple cytokine combinations and TGF-beta on differentiation and functions of myeloidderived suppressor cells. Int J Mol Sci. 2018;19(3):869.

171. Papaspyridonos M, Matei I, Huang Y, do Rosario Andre M, Brazier-Mitouart $\mathrm{H}$, Waite JC, et al. Id1 suppresses anti-tumour immune responses and promotes tumour progression by impairing myeloid cell maturation. Nat Commun. 2015;6:6840.

172. Jayaraman P, Parikh F, Newton JM, Hanoteau A, Rivas C, Krupar R, et al. TGFbeta1 programmed myeloid-derived suppressor cells (MDSC) acquire immune-stimulating and tumor killing activity capable of rejecting established tumors in combination with radiotherapy. Oncoimmunology. 2018;7(10):e1490853

173. Ferguson-Smith AC, Chen YF, Newman MS, May LT, Sehgal PB, Ruddle FH. Regional localization of the interferon-beta 2/B-cell stimulatory factor 2/ hepatocyte stimulating factor gene to human chromosome 7p15-p21. Genomics. 1988;2(3):203-8.

174. Li ZW, Sun B, Gong T, Guo S, Zhang J, Wang J, et al. GNAl1 and GNAl3 reduce colitis-associated tumorigenesis in mice by blocking IL6 signaling and down-regulating expression of GNAI2. Gastroenterology. 2019;156(8): 2297-312.

175. Bergerot $P$, Lamb P, Wang E, Pal SK. Cabozantinib in combination with immunotherapy for advanced renal cell carcinoma and urothelial carcinoma: rationale and clinical evidence. Mol Cancer Ther. 2019;18(12): 2185-93.

176. Choueiri TK, Powles T, Burotto M, Escudier B, Bourlon MT, Zurawski B, et al. Nivolumab plus cabozantinib versus sunitinib for advanced renal-cell carcinoma. N Engl J Med. 2021;384(9):829-41.

177. Davis RJ, Moore EC, Clavijo PE, Friedman J, Cash H, Chen Z, et al. Anti-PD-L1 efficacy can be enhanced by inhibition of myeloid-derived suppressor cells with a selective inhibitor of PI3K $/ \gamma$. Cancer Res. 2017;77(10):2607-19.

178. Stiff A, Trikha P, Wesolowski R, Kendra K, Hsu V, Uppati S, et al. Myeloidderived suppressor cells express Bruton's tyrosine kinase and can be depleted in tumor-bearing hosts by ibrutinib treatment. Cancer Res. 2016; 76(8):2125-36.

179. Hashimoto A, Fukumoto T, Zhang R, Gabrilovich D. Selective targeting of different populations of myeloid-derived suppressor cells by histone deacetylase inhibitors. Cancer Immunol Immunother. 2020.

180. Guha P, Gardell J, Darpolor J, Cunetta M, Lima M, Miller G, et al. STAT3 inhibition induces Bax-dependent apoptosis in liver tumor myeloid-derived suppressor cells. Oncogene. 2019;38(4):533-48.

181. Flores-Toro JA, Luo D, Gopinath A, Sarkisian MR, Campbell JJ, Charo IF, et al. CCR2 inhibition reduces tumor myeloid cells and unmasks a checkpoint inhibitor effect to slow progression of resistant murine gliomas. Proc Natl Acad Sci U S A. 2020;117(2):1129-38.

182. Mu XY, Wang RJ, Yao ZX, Zheng Z, Jiang JT, Tan MY, et al. RS 504393 inhibits M-MDSCs recruiting in immune microenvironment of bladder cancer after gemcitabine treatment. Mol Immunol. 2019;109:140-8.

183. Nefedova Y, Fishman M, Sherman S, Wang X, Beg AA, Gabrilovich DI. Mechanism of all-trans retinoic acid effect on tumor-associated myeloidderived suppressor cells. Cancer Res. 2007;67(22):11021-8.

184. Bauer R, Udonta F, Wroblewski M, Ben-Batalla I, Santos IM, Taverna F, et al. Blockade of myeloid-derived suppressor cell expansion with all-trans retinoic acid increases the efficacy of antiangiogenic therapy. Cancer Res. 2018;78(12):3220-32

185. Kang TH, Knoff J, Yeh WH, Yang B, Wang C, Kim YS, et al. Treatment of tumors with vitamin E suppresses myeloid derived suppressor cells and enhances CD8+ T cell-mediated antitumor effects. PloS One. 2014;9(7):e103562.

186. Young MR, Day TA. Immune regulatory activity of vitamin $\mathrm{d} 3$ in head and neck cancer. Cancers (Basel). 2013;5(3):1072-85.

187. Lathers DM, Clark Jl, Achille NJ, Young MR. Phase 1B study to improve immune responses in head and neck cancer patients using escalating doses of 25-hydroxyvitamin D3. Cancer Immunol Immunother. 2004;53(5):422-30.

188. Fleet JC, Burcham GN, Calvert RD, Elzey BD, Ratliff TL. 1a, 25 Dihydroxyvitamin $D(1,25(\mathrm{OH})(2) \mathrm{D})$ inhibits the $T$ cell suppressive function of myeloid derived suppressor cells (MDSC). J Steroid Biochemistry Mol Biol. 2020;198:105557.

189. Kuwata T, Wang IM, Tamura T, Ponnamperuma RM, Levine R, Holmes KL, et al. Vitamin A deficiency in mice causes a systemic expansion of myeloid cells. Blood. 2000;95(11):3349-56.
190. Serafini P, Meckel K, Kelso M, Noonan K, Califano J, Koch W, et al. Phosphodiesterase-5 inhibition augments endogenous antitumor immunity by reducing myeloid-derived suppressor cell function. J Exp Med. 2006; 203(12):2691-702

191. Miret JJ, Kirschmeier P, Koyama S, Zhu M, Li YY, Naito Y, et al. Suppression of myeloid cell arginase activity leads to therapeutic response in a NSCLC mouse model by activating anti-tumor immunity. J Immunother Cancer. 2019;7(1):32.

192. Li L, Wang L, Li J, Fan Z, Yang L, Zhang Z, et al. Metformin-induced reduction of CD39 and CD73 blocks myeloid-derived suppressor cell activity in patients with ovarian cancer. Cancer research. 2018;78(7):1779-91.

193. Jayaprakash P, Ai M, Liu A, Budhani P, Bartkowiak T, Sheng J, et al. Targeted hypoxia reduction restores $T$ cell infiltration and sensitizes prostate cancer to immunotherapy. J Clin Invest. 2018;128(11):5137-49.

194. Xie Z, Ikegami T, Ago Y, Okada N, Tachibana M. Valproic acid attenuates CCR2-dependent tumor infiltration of monocytic myeloid-derived suppressor cells, limiting tumor progression. Oncoimmunology. 2020;9(1): 1734268 .

195. Yin T, Zhao ZB, Guo J, Wang T, Yang JB, Wang C, et al. Aurora A inhibition eliminates myeloid cell-mediated immunosuppression and enhances the efficacy of anti-PD-L1 therapy in breast cancer. Cancer Res. 2019;79(13):3431-44.

196. Ko JS, Rayman P, Ireland J, Swaidani S, Li G, Bunting KD, et al. Direct and differential suppression of myeloid-derived suppressor cell subsets by sunitinib is compartmentally constrained. Cancer Res. 2010;70(9):3526-36.

197. Heine A, Schilling J, Grünwald B, Krüger A, Gevensleben H, Held SA, et al. The induction of human myeloid derived suppressor cells through hepatic stellate cells is dose-dependently inhibited by the tyrosine kinase inhibitors nilotinib, dasatinib and sorafenib, but not sunitinib. Cancer Immunol Immunother. 2016;65(3):273-82.

198. Sumida K, Wakita D, Narita Y, Masuko K, Terada S, Watanabe K, et al. Anti-IL6 receptor mAb eliminates myeloid-derived suppressor cells and inhibits tumor growth by enhancing T-cell responses. Eur J Immunol. 2012;42(8): 2060-72.

199. Shen L, Sundstedt A, Ciesielski M, Miles KM, Celander M, Adelaiye R, et al. Tasquinimod modulates suppressive myeloid cells and enhances cancer immunotherapies in murine models. Cancer Immunol Res. 2015;3(2):136-48.

200. Pico de Coaña Y, Poschke I, Gentilcore G, Mao Y, Nyström M, Hansson J, et al. Ipilimumab treatment results in an early decrease in the frequency of circulating granulocytic myeloid-derived suppressor cells as well as their Arginase1 production. Cancer Immunol Res. 2013;1(3):158-62.

201. Jochems C, Tucker JA, Tsang KY, Madan RA, Dahut WL, Liewehr DJ, et al. A combination trial of vaccine plus ipilimumab in metastatic castrationresistant prostate cancer patients: immune correlates. Cancer Immunol Immunother. 2014:63(4):407-18.

202. Li BH, Garstka MA, Li ZF. Chemokines and their receptors promoting the recruitment of myeloid-derived suppressor cells into the tumor. Mol Immunol. 2020;117:201-15.

203. Long GV, Dummer R, Hamid O, Gajewski TF, Caglevic C, Dalle S, et al. Epacadostat plus pembrolizumab versus placebo plus pembrolizumab in patients with unresectable or metastatic melanoma (ECHO-301/KEYNOTE252): a phase 3, randomised, double-blind study. Lancet Oncol. 2019;20(8): 1083-97.

204. Park JA, Wang L, Cheung NV. Modulating tumor infiltrating myeloid cells to enhance bispecific antibody-driven T cell infiltration and anti-tumor response. J Hematol Oncol. 2021:14(1):142.

\section{Publisher's Note}

Springer Nature remains neutral with regard to jurisdictional claims in published maps and institutional affiliations. 